\title{
Congestion Management Requirements, Methods and Performance Indices
}

\section{June 2002}

Prepared by

B. J. Kirby, J. W. Van Dyke

Oak Ridge National Laboratory

C. Martinez, A. Rodriguez

Electric Power Group

Southern California Edison 


\section{DOCUMENT AVAILABILITY}

Reports produced after January 1, 1996, are generally available free via the U.S. Department of Energy (DOE) Information Bridge:

Web site: http://www.osti.gov/bridge

Reports produced before January 1, 1996, may be purchased by members of the public from the following source:

National Technical Information Service

5285 Port Royal Road

Springfield, VA 22161

Telephone: 703-605-6000 (1-800-553-6847)

TDD: $703-487-4639$

Fax: 703-605-6900

E-mail: info@ntis.fedworld.gov

Web site: http://www.ntis.gov/support/ordernowabout.htm

Reports are available to DOE employees, DOE contractors, Energy Technology Data Exchange (ETDE) representatives, and International Nuclear Information System (INIS) representatives from the following source:

Office of Scientific and Technical Information

P.O. Box 62

Oak Ridge, TN 37831

Telephone: 865-576-8401

Fax: 865-576-5728

E-mail: reports@adonis.osti.gov

Web site: http://www.osti.gov/contact.html

This report was prepared as an account of work sponsored by an agency of the United States Government. Neither the United States government nor any agency thereof, nor any of their employees, makes any warranty, express or implied, or assumes any legal liability or responsibility for the accuracy, completeness, or usefulness of any information, apparatus, product, or process disclosed, or represents that its use would not infringe privately owned rights. Reference herein to any specific commercial product, process, or service by trade name, trademark, manufacturer, or otherwise, does not necessarily constitute or imply its endorsement, recommendation, or favoring by the United States Government or any agency thereof. The views and opinions of authors expressed herein do not necessarily state or reflect those of the United States Government or any agency thereof.

This report was prepared as a result of work sponsored in part by the California Energy Commission. It does not necessarily represent the views of the Energy Commission, its employees, or the State of California. The Energy Commission, the State of California, its employees, contractors, and subcontractors make no warranty, express or implied, and assume no legal liability for the information in this report; nor does any party represent that the use of this information will not infringe upon privately owned rights. 


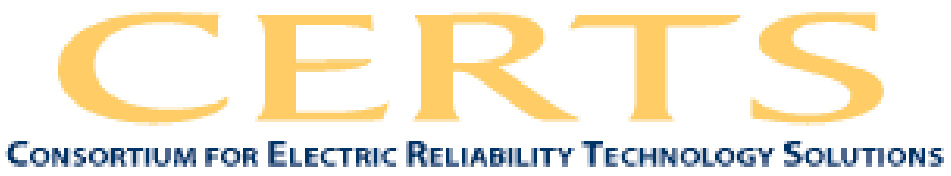

\title{
Congestion Management Requirements,
} Methods and

\section{Performance Indices}

\section{Consortium for Electric Reliability Technology Solutions}

\author{
Prepared for the \\ Transmission Reliability Program \\ Office of Power Technologies \\ Assistant Secretary for Energy Efficiency and Renewable Energy \\ U. S. Department of Energy \\ Principal Authors \\ Brendan Kirby and Jim Van Dyke \\ Oak Ridge National Laboratory \\ Carlos Martinez and Alonso Rodriguez \\ Electric Power Group \\ June 2002 \\ CERTS - Real-time Grid Monitoring and Management
}

The work described in this report was coordinated by the Consortium for Electric Reliability Technology Solutions on behalf of the California Enery Commission, the Assistant Secretary for Energy Efficiency and Renewable Energy, Office of Power Technologies, Transmission Reliability Program of the U. S. Department of Energy under Contract No. DE-AC03-76SF00098.

Prepared by

Oak Ridge National Laboratory

Oak Ridge, Tennessee 37831-6070

Managed by

UT-BATTELLE, LLC

for the

U. S. Department of Energy

under contract DE-AC05-00OR22725 



\section{Table of Contents}

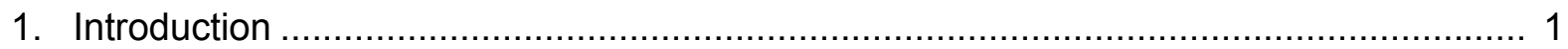

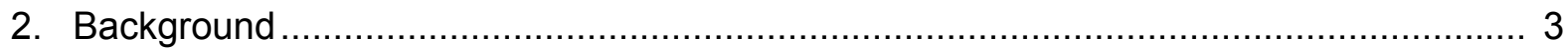

2.1. The Importance of Congestion Management................................................. 3

2.2. Economic Implications of Congestion Management ....................................... 5

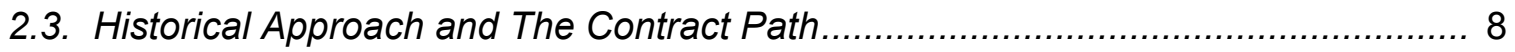

2.4. Congestion Management and Market Design.............................................. 9

2.5. Problems and Challenges for Implementing Market Based

Congestion Management_Centralized Versus Decentralized Systems ................. 10

2.6. PJM Interconnection-A Centralized Approach Based on Locational Marginal

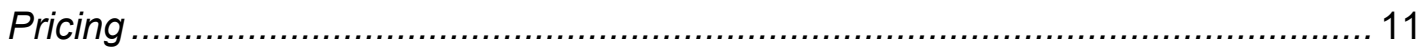

2.7. Decentralized Approaches with Property Rights Based on Zones and Flowgates 12

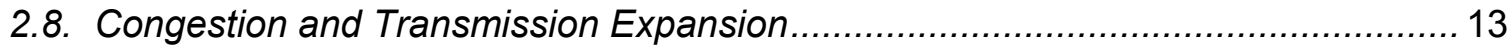

3. FERC, NERC, and Regional Reliability Councils.............................................. 15

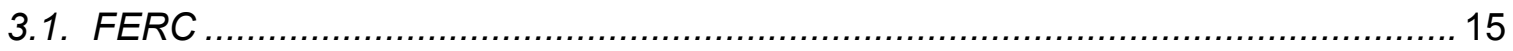

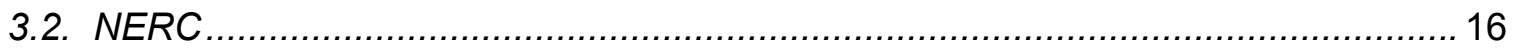

3.3. Regional Reliability Councils_WSCC as an Example ..................................... 19

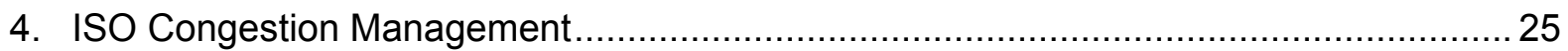

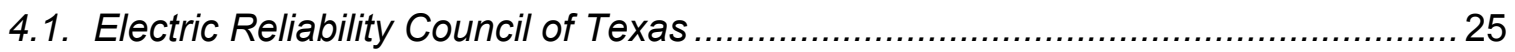

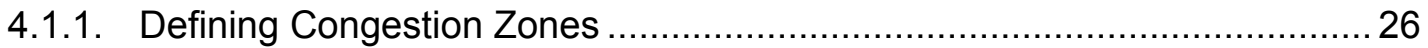

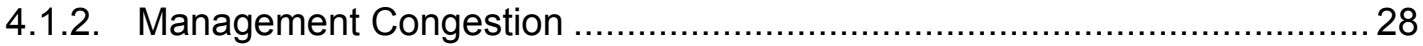

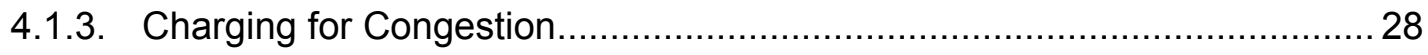

4.1.4. Congestion Management Improvements ............................................29

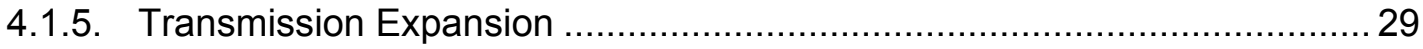

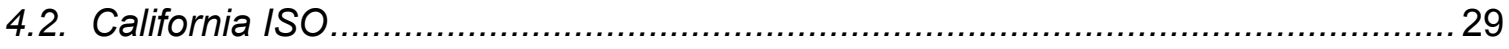


4.2.1 Defining Congestion Zones ...................................................... 30

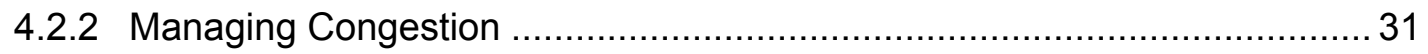

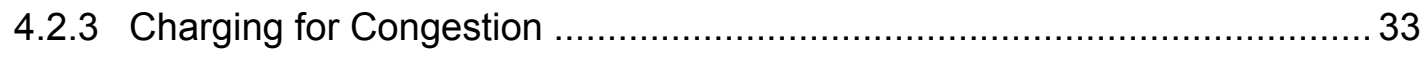

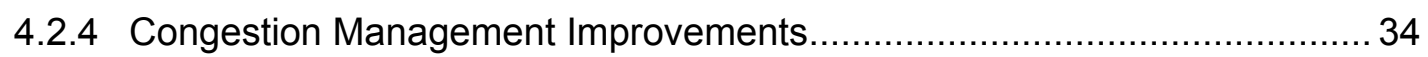

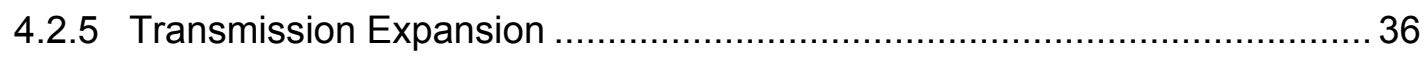

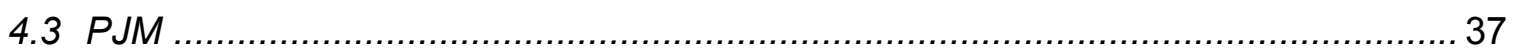

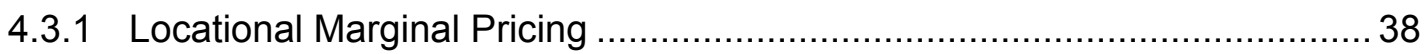

4.3.2 Determining Locational Marginal Prices ................................................ 39

4.3.3 Markets for Fixed Transmission Rights ............................................ 39

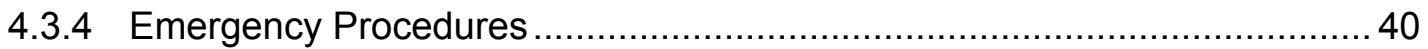

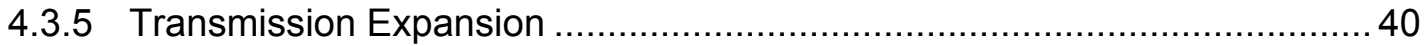

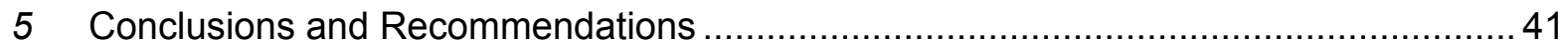

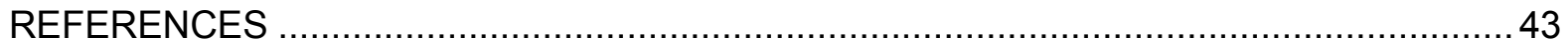




\section{List of Figures}

2.1 NERC's 10 regional councils cover the 48 contiguous states, most of Canada, and a portion of Mexico............................................................................................. 3

2.2 Transmission congestion is aggravated by the fact that transmission capacity relative to peak load has declined in every region of the U.S. for the past ten years and is expected to continue declining for the next ten.................................................... 4

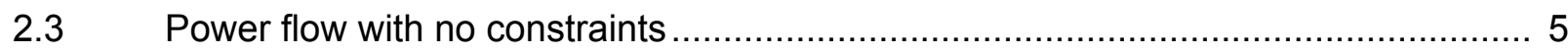

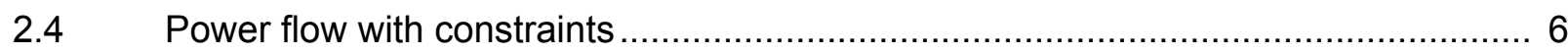

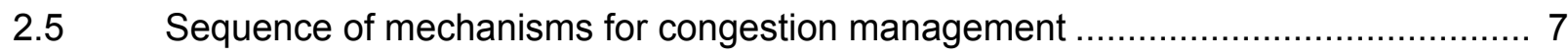

3.1 NERC's 10 regional councils cover the 48 contiguous states, most of Canada, and a portion of Mexico.

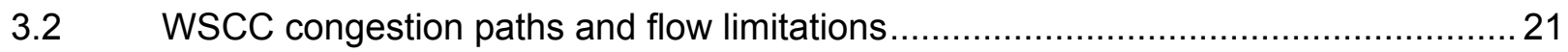

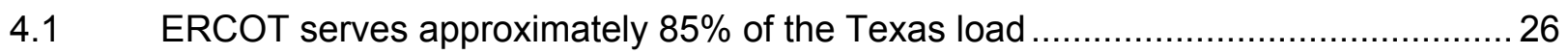

4.1.1 ERCOT currently has three commercially signification congestion zones ...............27

4.2.1 The CA ISO's transmission system serves approximately $75 \%$ of the state and consists of three internal congestion zones connecting to nine external zones.

4.3.1 PJM Locational Marginal Pricing Model 38 



\section{Acronyms}

ACT Available Transfer Capability

CAISO California Independent System Operator

ECAR East Central Area Reliability Coordination Agreement

ERCOT Electric Reliability Council of Texas

FERC Federal Energy Regulatory Commission

FRCC Florida Reliability Coordinating Council

FTR Financial Transmission Rights, Firm Transmission Rights, or

Fixed Transmission Rights

GWH Gigawatt-Hour

ISO Independent System Operator

LMP Locational Marginal Price

LPA Locational Price Algorithm

MAAC Mid-Atlantic Area Council

MAIN Mid-America Interconnected Network, Inc.

MAPP Mid-Continent Area Power Pool

MW Megawatt

$\mathrm{MWH} \quad$ Megawatt-Hour

NERC North American Electric Reliability Council

NPCC Northeast Power Coordinating Council

NYISO New York Independent System Operator

OASIS Open Access Same-Time Information System

PJM Pennsylvania-New Jersey-Maryland Interconnection

PX Power Exchange Market

RTO Regional Transmission Organization 


$\begin{array}{ll}\text { SERC } & \text { Southeastern Electric Reliability Council } \\ \text { SPP } & \text { Southwest Power Pool, Inc. } \\ \text { SO } & \text { System Operator (transmission) } \\ \text { TCR } & \text { Transmission Congestion Rights } \\ \text { TLR } & \text { Transmission Loading Relief } \\ \text { TTC } & \text { Total Transmission Capability } \\ \text { WSCC } & \text { Western Systems Coordinating Council }\end{array}$




\section{Introduction}

Transmission congestion occurs when there is insufficient transmission capacity to simultaneously accommodate all requests for transmission service within a region. Historically, vertically integrated utilities managed this condition by constraining the economic dispatch of generators with the objective of ensuring security and reliability of their own and/or neighboring systems. Electric power industry restructuring has moved generation investment and operations decisions into the competitive market but has left transmission as a communal resource in the regulated environment. This mixing of competitive generation and regulated transmission makes congestion management difficult. The difficulty is compounded by increases in the amount of congestion resulting from increased commercial transactions and the relative decline in the amount of transmission. Transmission capacity, relative to peak load, has been declining in all regions of the U.S. for over a decade. This decline is expected to continue.

Congestion management schemes used today have negative impacts on energy markets, such as disruptions and monetary penalties, under some conditions. To mitigate these concerns various congestion management methods have been proposed, including redispatch and curtailment of scheduled energy transmission. In the restructured electric energy industry environment, new congestion management approaches are being developed that strive to achieve the desired degree of reliability while supporting competition in the bulk power market.

This report first presents an overview and background on key issues and emerging approaches to congestion management. It goes on to identify and describe policies affecting congestion management that are favored and/or are now being considered by FERC, NERC, and one of the regional reliability councils (WSCC). It reviews the operational procedures in use or proposed by three of the leading independent system operators (ISOs) including ERCOT, California ISO, and PJM. Finally, it presents recommendations for evaluating the competing alternative approaches and developing metrics to use in such evaluations.

As with any report concerning electricity restructuring, specific details quickly become dated. Individual utilities, states and regions will inevitably change rules and procedures even during the time it takes to publish a report. Hopefully, the general conclusions are more robust and this report will continue to have value even after some of the specific details have changed. 


\section{Background}

\subsection{The Importance of Congestion Management}

Transmission congestion has a specific meaning for electrical systems. It can be defined as the condition where desired transmission line-flows exceed reliability limits. Following this definition, congestion management can be defined as the actions taken to avoid or relieve congestion. More broadly, congestion management can be considered any systematic approach used in scheduling and matching generation and loads in order to manage congestion.

Fig. 2.1: NERC's 10 regional councils cover the 48 contiguous states, most of Canada, and a portion of Mexico.

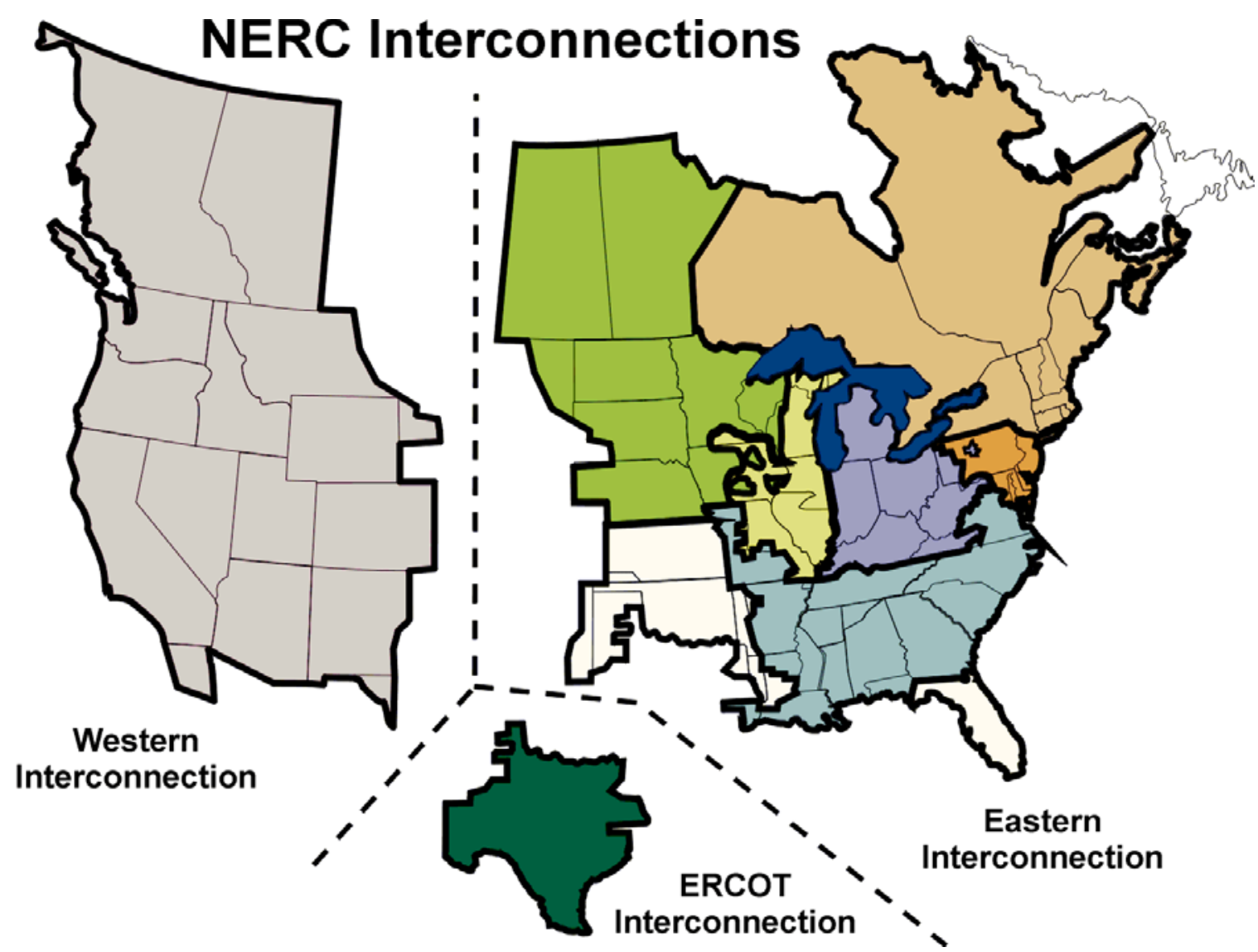

An overview of the North American transmission network provides a starting point for understanding congestion management issues. The North American electric system is divided into three Interconnections (see Figure 2.1): the Western Interconnection (Western Systems Coordinating Council [WSCC]), the Electric Reliability Council of Texas (ERCOT, which covers most of Texas), and the Eastern Interconnection (all Reliability Councils except WSCC and ERCOT). Within each Interconnection, all the 
generators operate at the same frequency as essentially one machine connected to each other and to loads primarily by AC lines. The Interconnections are connected to each other by a few DC links. Because these DC connections are limited, the flows of electricity and markets are much greater within each Interconnection than between Interconnections.

Within each Interconnection the fundamental entity responsible for maintaining bulkpower reliability (and therefore congestion management) is the control area. NERC defines control areas as: "An electric system or systems, bounded by interconnection metering and telemetry, capable of controlling generation to maintain its interchange schedule with other Control Areas and contributing to frequency regulation of the Interconnection." (NERC 2001a) Control areas are linked to one another to form Interconnections. Each control area seeks to minimize any adverse effect it might have on other control areas within the Interconnection by (1) matching its schedules with other control areas (i.e., how well it matches its generation plus net incoming scheduled flows to its loads) and (2) helping the Interconnection to maintain frequency at its scheduled value (nominally $60 \mathrm{~Hz}$ ).

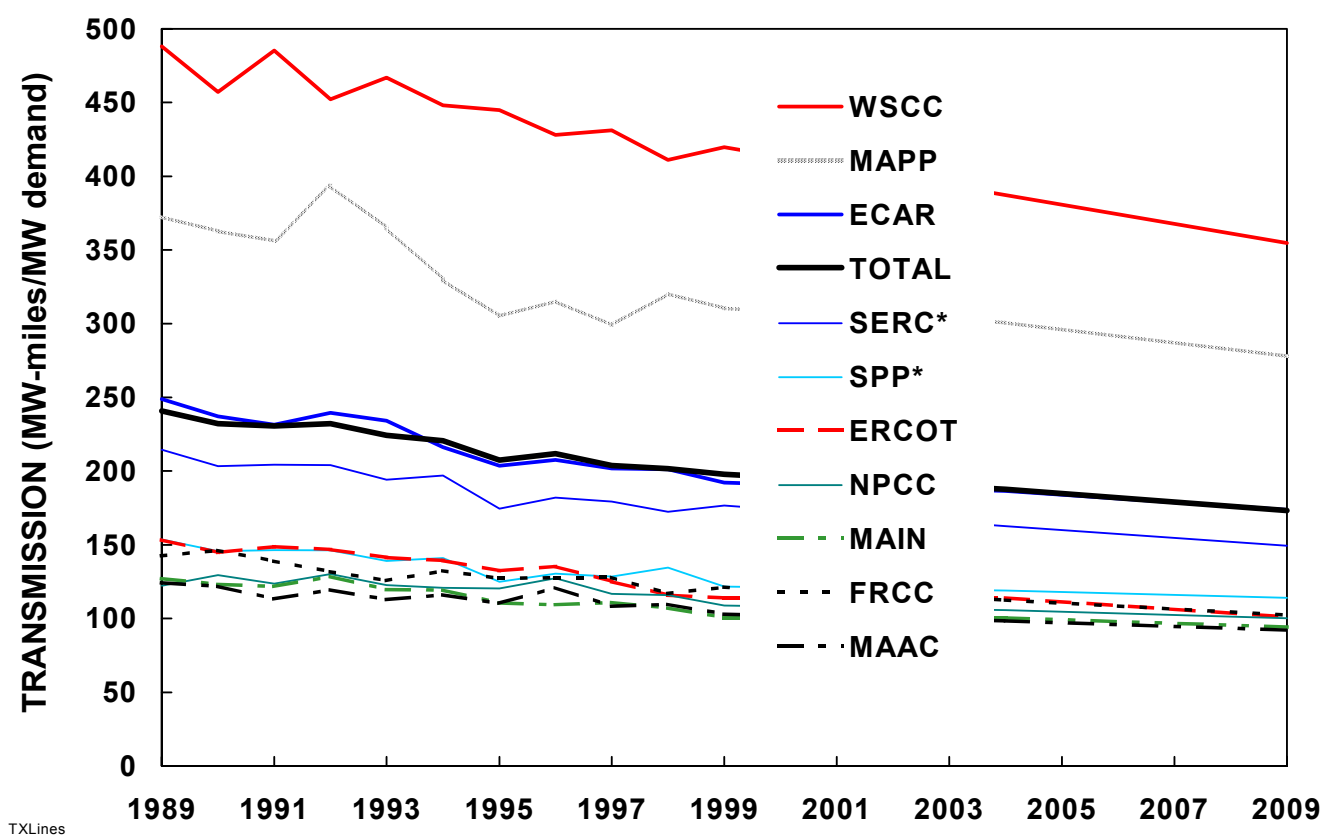

Fig. 2.2. Transmission congestion is aggravated by the fact that transmission capacity relative to peak load has declined in every region of the U.S. for the past ten years and is expected to continue declining for the next ten.

Today's approximately 150 control areas are operated primarily by utilities, although a few are run by ISOs. Control areas vary enormously in size, with several managing less than $100 \mathrm{MW}$ of generation and, at the other end of the spectrum, PJM (PennsylvaniaNew Jersey-Maryland Interconnection), California ISO, and ERCOT each managing about 50,000 MW of generation. Control areas are grouped into regional reliability councils, of which there are 10 in North America. These reliability regions, in turn, are parts of the three Interconnections. 
Figure 2.2 provides one indication of the growing importance of congestion management. As this figure indicates, transmission capacity relative to peak load has been declining and will continue to decline for every region in the U.S.

\subsection{Economic Implications of Congestion Management}

The first responsibility of the transmission System Operator (SO), whether it is a large ISO or a small utility control area, is to maintain system reliability. This involves developing generation and load schedules that can be balanced in real time. The SO must make sure that the scheduled flows do not exceed a maximum for any link on the system. Scheduling generators and loads must carefully consider any transmission link that could potentially become constrained. This consideration includes not only the current flows on the system's lines and equipment, but it also must consider the postcontingency capacity. For any link the transmission system must provide enough capacity that any single contingency within the system (and any credible multiple contingency) could be handled.

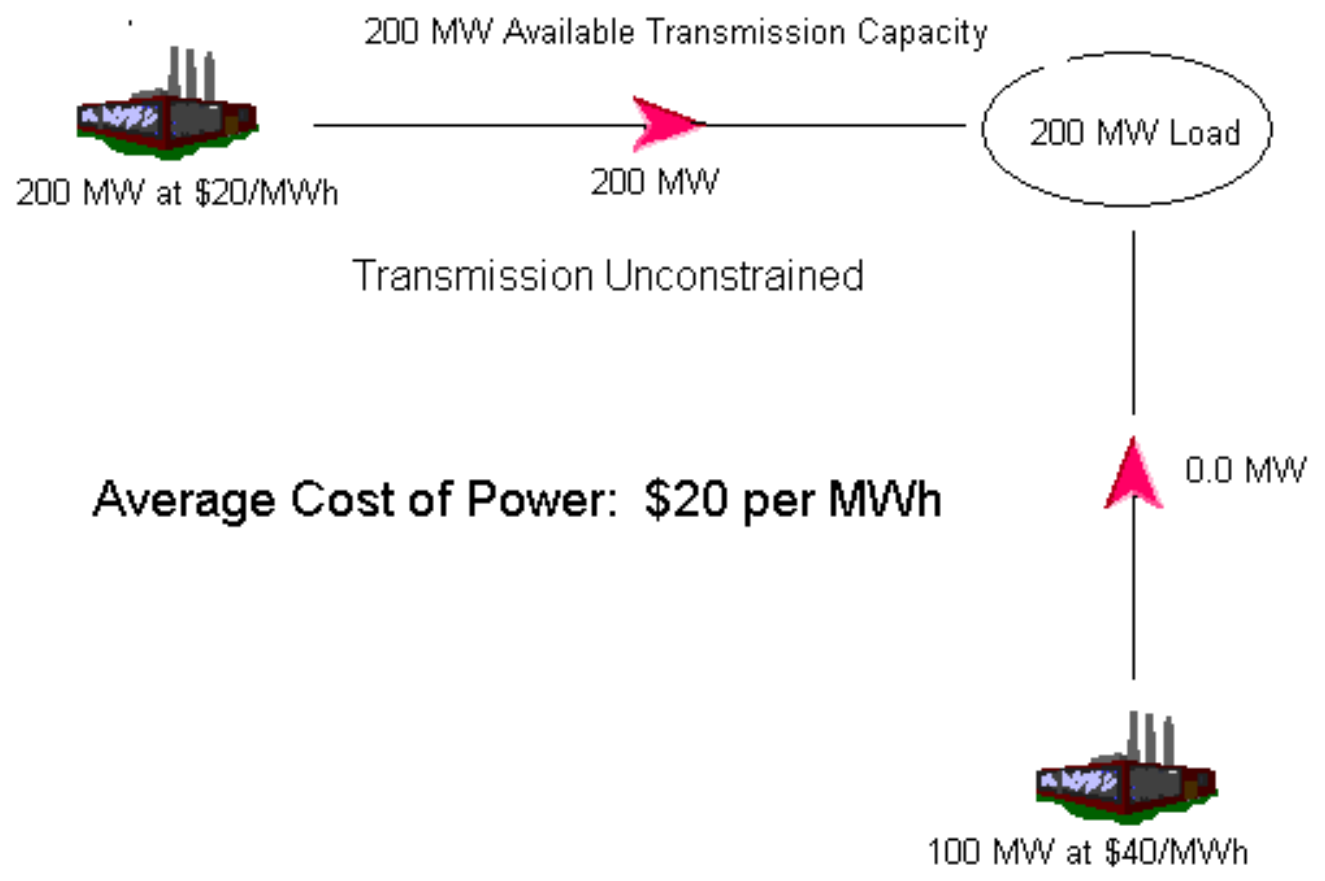

Fig. 2.3. Power flow with no constraints

Although the transmission system operates according to the physical laws of power flow, the economic implications for congestion management are equally important. Transmission congestion can be easily managed by curtailing generators and loads. However, arbitrarily restricting generators and loads can have significant economic costs. Figures 2.3 and 2.4 portray an example of why this is the case. 


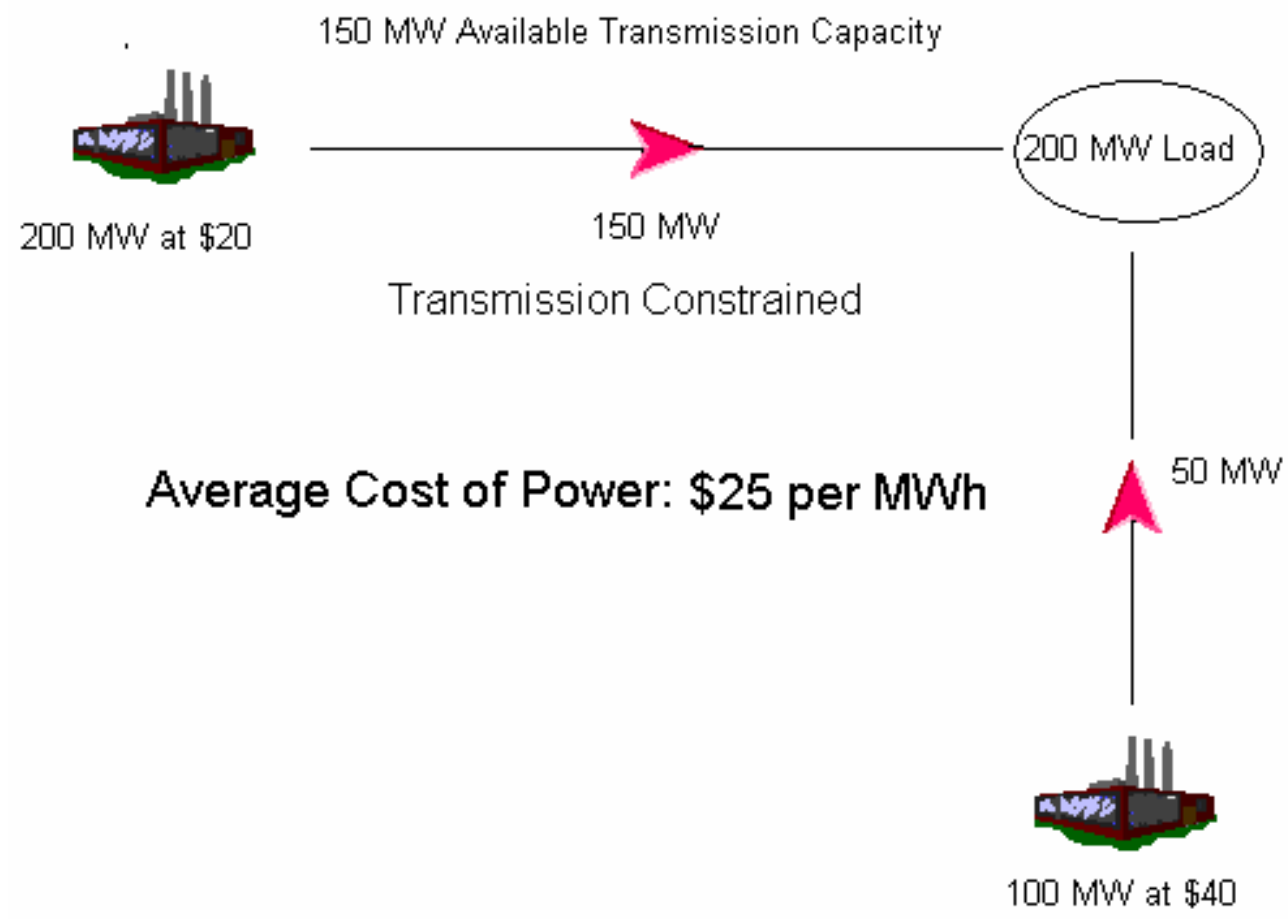

Fig. 2.4. Power flow with constraints

In Figure 2.3, there is no congestion. The $200 \mathrm{MW}$ load can be served with available power at $\$ 20$ per $\mathrm{MWH}$. However, in Figure 2.4, while the same generation source offers power at $\$ 20$ per $\mathrm{MWH}$, the available transfer capability has been reduced to 150 MW, less than the desired transfer of $200 \mathrm{MW}$. Now the remaining $50 \mathrm{MW}$ of power must be transferred over a different facility and purchased from a second generator that charges $\$ 40$ per $\mathrm{MWH}$. Thus for the $50 \mathrm{MW}$ increment, the cost of power purchased by the customer has doubled. The average cost to the customer for $200 \mathrm{MWH}$ has increased from $\$ 4,000$ to $\$ 5,000$ or by $25 \%$.

This example illustrates why transmission congestion is potentially important from an economic standpoint. While, the principle is simple, the balancing of reliability and commercial interests can be complex in the detail. In order to schedule transmission services reliably and economically, the SO must understand the available transfer capability (ATC) as defined by physical capacities and the scheduled flows. If the ATC is over-estimated, then real-time congestion could result in reducing system reliability below acceptable levels. On the other hand, if the ATC is under estimated, then economic exchanges are potentially foregone. For instance, if the actual ATC in Figure 2.4 is $200 \mathrm{MW}$, while the SO has limited its use to $150 \mathrm{MW}$, then the economic loss to the load is $\$ 1,000$ per hour. If the power costs in Figure 2.4 reflect the marginal social costs to generate power, then the unnecessary social loss is also $\$ 1,000$ per hour. There are also financial costs and benefits to the generators. By not serving the load, the $\$ 20$ per MWH generator will lose $\$ 1,000$ in revenue while the $\$ 40$ per MWH generator will gain $\$ 2,000$ in revenue. The load will pay an additional $\$ 1,000$ in electric costs. 
There is an important distinction here. That is, congestion can be managed, before the fact, with information provided from the scheduling period only if ATC is known. However, congestion must be managed in real-time if ATC is wrong. And real-time management of congestion is inherently less economically efficient because dispatch options are limited. Figure 2.5 depicts the sequence of mechanisms available for congestion management.

Fig. 2.5. Sequence of mechanisms for congestion management

PERIOD PRIOR TO SCHEDULING

SCHEDULING

REAL TIME ADJUSTMENTS
Forward Markets:

Bi-lateral Contracts

Spot Market

Submitted Schedules

Adjustments to submitted schedules based on ATC

Dispatch of voluntary resources under SO's control including adjustment bids

Involuntary Actions: TLR

The fundamental point is that if ATC is wrong during the scheduling period when there is the attempt to efficiently allocate transmission capacity, the SO can still maintain system reliability through real-time adjustments. Reliability is not compromised, however, economics may suffer. This can happen because the calculation of ATC depends upon forecasts of load and generation patterns throughout the system. If the forecast is wrong, then the ATC calculation can be wrong.

Figures 2.3 and 2.4 demonstrate another important point about transmission congestion. Without congestion, the marginal cost to supply an increment of load is determined by the lowest marginal cost generator on the system and is the same for any load on the system (see Figure 2.3). However, with congestion the marginal cost to supply an increment of load is determined by location. The marginal cost for a given location is the lowest cost increment of generation supply with available transmission capacity between the generation source and the load. 


\subsection{Historical Approach and The Contract Path}

The historical approach to congestion management was developed based on the operations of integrated utilities. These utilities developed integrated generation and transmission networks. Generating units were planned and located within the framework of available transmission facilities. Although transmission could become congested because of unanticipated load growth or the availability of neighboring generation, these problems were for the most part "internal" to the utility. The utility could develop additional transmission facilities or new generation to solve its own problems. The utility dispatched its own generation resources to meet its system reliability objectives at minimum cost. Transmission links to other utilities and control areas were mainly used to reduce reserve margins through diversity. While, power exchanges took place between utilities, they were usually based upon mutual agreement with each utility maintaining control over use of its own transmission facilities.

However, even in the era before restructuring and open transmission access, there were disputes over the use of third party transmission or "wheeling" of power. The transmission owner had the right to be compensated for use of transmission facilities. However, the actual physical path of transferring power over large distances within an integrated transmission grid was problematic. In fact the power got from the generating source to the load over many parallel paths. In order to define the "path" for purposes of making the transaction, utilities developed a convenient fiction. If there existed a transmission path with sufficient capacity between the generator and the load this was defined as the "contract path." This approach was practicable when most generation and loads were still matched within the same utility service area. However, in the advent of restructuring and competition for bulk power, this contract path approach is no longer viable. Transmission planners did not anticipate the exchange of large amounts of power over long distances. The result is a large increase in loop flows, which can be defined as the physical flow of power when it does not correspond to the contractual flow. In essence, the relevant systems of generation and transmission resources that must be coordinated have become much larger and more complicated.

These larger power and transmission systems include multiple utility service areas controlled by SOs or ISOs. The term "Independent" connotes their independence from the participants in the bulk power market. Examples of ISOs include the CAISO (California ISO), the NYISO (New York ISO), the ISO New England, the ERCOT and the PJM Interconnection. The central role of the SO or ISO is to coordinate the schedule of resources and loads within a transmission network in order to maintain system reliability and to facilitate the operation of a competitive market for bulk power. Thus, the challenge of managing transmission congestion falls on the SO. 


\subsection{Congestion Management And Market Design}

The driving force of utility restructuring is competition of power generators for electric customers and loads. As pointed out above (see Figures 2.3 and 2.4) transmission resources can be a complicating factor in the competition based on the price of power generation. The main challenge for congestion management is how it can be structured so that it efficiently supports competition in the bulk power market.

Perhaps the dilemma of congestion management is best seen through the operation of Transmission Loading Relief (TLR). TLR has several inherent inefficiencies in the electric energy market. TLR depends strongly on the determination of total transmission capability (TTC) or the amount of power that can be transmitted between two points, and also on the available transfer capability or the amount of power that can be transmitted between two points simultaneously with other transactions and reserves needed for reliability. However, ATC costs are not considered in the calculations, and the method's inherent lack of accuracy and uncertainty can result in either underutilization or overselling of transmission line capacity.

Under congestion conditions that threaten reliability, TLR is activated by an administrative rule and not by economic considerations. Administrative curtailments can lead to congestion charges that are higher than transmission provider charges. This difference in charges is 'left over', and market participants game the TLR rules to take this money by submitting transactions which would never materialize but will position them to be curtailed less and force others to be curtailed more. Under TLR, congested transmission is not offered to the highest bidder and the effects of counter-flow trades are not credited against other trades, which all adds to the inefficiency of this congestion management method.

A simple example illustrates the problem with this approach. Assume a case where congestion results on a system in which there are only two users on a congested facility, each using $50 \%$ of the capacity. User $A$ has a contract to receive power at $\$ 20$ per $\mathrm{MWH}$ and User $\mathrm{B}$ has a contract to receive power at $\$ 40$ per $\mathrm{MWH}$. When their transactions are curtailed, each user can replace the power for $\$ 41$ per $\mathrm{MWH}$. Curtailing each user an equal amount is economically inefficient because the value to use the congested facility is much greater per $\mathrm{MWH}$ for User $\mathrm{A}(\$ 41-\$ 20=\$ 21)$ compared to User B $(\$ 41-\$ 40=\$ 1)$. The ideal congestion management system would allow competitive forces to efficiently determine which transactions should be reduced to avoid congestion. Using this competitive criteria would utilize the transmission system to support the highest value of power exchange as determined by the cost and location of generation resources and loads within the system.

To be successful, any system to allocate scarce transmission resources must attempt to find the set of transactions that maximize the value of using the congested facilities. This set of transactions will fully use the congested capacity up to the required level of reliability. The information necessary for achieving this must be generated prior to the real-time system operation in time to create a workable schedule. 
For any congestion management approach, there is a scheduling period where transmission availability is in full play and a period of real time adjustments where the SO must balance generation and load with system resources under his control. The scheduling period is an opportunity for forward markets to allocate available transmission capacity. These forward markets can operate from months or days up to hours ahead of the real-time system operation.

Forward markets are considered a key factor in generating the information necessary to value alternative uses for congested facilities. Theoretically, the interplay of market forces will result in providing the right to use congested facilities to those market participants that place the highest value on their use.

To the extent that the combination of power resources and transmission availability can be efficiently allocated in this scheduling period, congestion management will be efficient. However, for several reasons this objective is problematic. Some of the problems will be discussed in the next section.

\subsection{Problems And Challenges For Implementing Market-Based Congestion Management-Centralized Versus Decentralized Systems}

The essential problem for efficiently combining competitive power markets with congestion management is in defining the property right to transmission in such a way that it can efficiently allocate the ATC within the structure of a competitive market process. One inherent difficulty is that the ATC for any transmission link depends on the utilization of all other links within the network. Therefore, each change in scheduled generation and load within the system affects the ATC for all links on the system. This creates a moving target for matching a property right to ATC. Another difficulty is that because of parallel power flows across the system, any transaction uses many links as power flows from the generation point to the load ${ }^{1}$. How can transmission rights be defined so that transactions are not overly complicated by the need to purchase rights for multiple transmission links between the power source and the load? Unless transmission rights can be adequately defined it will be difficult or inefficient to trade them within a competitive market. Transmission rights may be defined as physical rights or financial rights. They are often ambiguously labeled as FTRs, which might stand for Financial Transmission Rights, Firm Transmission Rights, or Fixed Transmission Rights. Ziad Alaywan of the California ISO (Alaywan 2001) describes three alternative FTR structures:

Physical Rights Model. This FTR model only considers scheduling rights. The FTR owners schedule across inter-zonal interfaces. Any FTR that is not used in the dayahead market will be released in the hour-ahead market for others to use without

\footnotetext{
${ }^{1}$ Transmission use is determined based on power transfer distribution factors (PTDF). These factors are based on transmission flow models that translate the physical effects of each energy transaction into requirements of transmission rights and transmission loss coverage
} 
retaining the financial rights. The market participants that do not own FTRs can buy FTRs through the secondary markets.

Mix of Physical and Financial Rights Model. In this model, FTRs provide scheduling priority as well as financial rights. FTRs are not the only way to schedule a transaction on the transmission system. FTRs that are not sold in the day-ahead market are released in the hour-ahead markets, but the original owner retains the financial rights. The FTRs also provide a higher priority of scheduling services in the case where the ISO has to allocate transmission capability in the absence of economic signals such as adjustment bids. Adjustment bids allow the FTR holders to sell their FTR rights in the day-ahead market if the price is right.

Financial Rights Model. In this model, the FTR holder privileges are limited to financial rights. FTRs are not needed to schedule a transaction on the transmission system and do not provide higher-priority service when the ISO has to reduce schedules. The FTR owner receives payments.

Although there are several alternative proposals for incorporating congestion management into competitive markets for bulk power, they can be divided into two types: centralized and decentralized.

\subsection{PJM Interconnection-A Centralized Approach Based on Locational Marginal Pricing}

The centralized approach is exemplified by The PJM Interconnection. Historically, PJM has been a centrally dispatched power pool. Members put their generation resources at the disposal of the pool and they are centrally dispatched to minimize system costs. This is the traditional approach of utilities. However, because PJM is a power pool it incorporates the generation resources of several utilities resulting in the largest centrally dispatched system in North America.

PJM achieves congestion management through its centralized control of generation resources. The system operation utilizes a computer program that minimizes the cost of dispatching generation resources subject to the transmission constraints (see Section 4.3). Market incentives for power and transmission are combined through a system of Locational Marginal Prices (LMPs). These LMPs are determined for 1,750 busses within the PJM system. The LMP is determined by the system marginal generating cost plus the "shadow price" on the transmission constraints specific to location of the generation and the load busses. These LMPs are posted on the OASIS system (Internet) every five minutes so they are essentially known in real time. The congestion shadow price is the incremental cost of redispatching the system due to the transmission constraint.

PJM provides a market that allows participants to financially hedge their transactions through FTRs. The FTRs are initially auctioned and then traded in secondary markets. 
Their role is to provide a hedge against the uncertainty of high LMPs caused by congestion. The purchase of FTRs in effect guarantees the purchaser the LMP at the generation buss regardless of the LMP at the load buss.

In effect, PJM provides two types of incentives to account for congestion. The LMPs indicate the charge for congestion. These charges for congestion are only determined after the fact; however, they provide historical information that helps inform and indirectly provides incentives for future transactions to anticipate congestion costs. Market demand for FTRs corresponding to congested nodes or hubs (FTRs for hubs are created by taking a weighted average of an aggregation of nodal FTRs) will increase the cost to hedge a transaction and signal the anticipated cost of congestion.

\subsection{Decentralized Approaches with Property Rights Based on Zones and Flowgates}

Decentralized systems rely on forward markets that generate bilateral transactions based on some form of transmission right. These forward markets are combined with a centralized spot market necessary to make balancing adjustments to the scheduled transmission. The key factor for these market-based systems to work efficiently is in defining the transmission right. These rights must accurately reflect transmission scarcity. Also, the trade and exchange of these rights should achieve an allocation that is economically efficient in controlling congestion throughout the system.

The transmission rights must reflect the marginal value of transmission availability where it would otherwise be in short supply (congested). Another requirement is that transmission rights are defined so that they are clearly understood and accepted by market participants. Finally, they must be of sufficient scope and interest that they are liquid in exchange markets. These various requirements are necessary to provide a rights that both accurately reflect the transmission scarcity and that have a broad enough interest to create a competitive market. If the rights are defined too broadly, they may not accurately reflect the scarce resource. If they are defined too specifically, there may not be enough interest to generate the advantages of a competitive market.

Current proposals for decentralized markets in transmission rights have defined them based on congestion between zones or congestion across "flowgates". Zones may be defined based on areas in which there tends to be relatively little congestion inside the zone (intra-zonal congestion). Therefore, only the congestion between zones (interzonal congestion) must be priced and allocated as opposed to all potentially congested paths. Property rights to transfer power between zones must reflect the available capacity so that congestion is avoided but available capacity is fully utilized.

An alternative formulation for a decentralized system is to define rights based on flowgates or commercially significant facilities. In this formulation, transmission rights are based on the transmission capacity of facilities or links that may potentially become congested. Their property rights are related to the physical transmission capacity and 
are allocated for the use of these flowgates. In theory, users would purchase the portfolio of flowgate rights that allowed the desired power transaction. There would be a market for flowgate rights after an initial auction of the available capacity.

Whether a centralized or decentralized system is better for congestion management has generated significant debate. An advantage of PJM's centralized system is the control that the SO has to operate the system efficiently through central dispatch. If the costs to dispatch generation resources are accurate, the LMPs can provide a very accurate accounting of congestion costs for the entire system. However, critics of centralized systems and LMPs say that because congestion charges can only be known after transactions have taken place, they do not allow the advantage of forward markets where participants can "discover" the advantages of trade by negotiating the price of transmission prior to the transaction.

Alternatively, decentralized systems are criticized as potentially unworkable without significant uplift charges for unanticipated congestion. Critics of the flowgate concept believe that the rights to flowgates cannot be correctly defined because they depend on ever changing contingencies (Ruff 2001). Another criticism is that the prices charged for using flowgates or commercially significant facilities will simply chase congestion to other parts of the system that are unpriced (Ott 2000). Then the redispatch costs to relieve congestion on the unpriced facilities must be covered by spreading costs (uplift charges). Critics maintain that, to the extent that congestion is simply shifted to other parts of the system and congestion costs are socialized to all users, the congestion management benefits of efficiently pricing transmission capacity will be lost.

\subsection{Congestion and Transmission Expansion}

Although congestion costs may be minimized by efficient congestion management strategies, an overarching concern is that the marginal cost of congestion should not be higher than the marginal cost of reducing congestion through investment in additional transmission capacity. In other words, high congestion costs should be a signal for expanding transmission capacity.

Although congestion management may be incorporated into market incentives, transmission owners are regulated and will therefore respond to the opportunities provided by regulators. Regulators must consider how the costs of congestion would be affected by increased investment in transmission facilities. In general, if congestion management is efficient, the economic costs of congestion are reduced to a minimum and the given set of transmission resources are used efficiently. Investing in transmission will always tend to increase reliability and reduce the costs of congestion. The key question is at what price?

One important connection between transmission investment and congestion management is that the marginal cost comparisons may look significantly different depending on whether congestion management is economically efficient. A dollar of 
investment in transmission capacity may have considerably different effects depending on how efficiently the existing transmission system is utilized. The efficiency of congestion management will also influence the type of transmission expansion and the location of new generation.

A more oblique connection between congestion management and transmission investment is the connection between the charges imposed for congestion and who receives the revenues they generate. One knee-jerk reaction might be that the congestion charges could revert to the transmission owners or the SO for investment in transmission facilities. This has the appeal of connecting the need to reduce congestion with a source of funds that runs in close parallel. However, this approach is wrong because it would create a perverse incentive for the transmission owners or the SO to maintain or increase congestion in order to increase the funds received.

The price signals indicating the cost of congestion are important as a signal for allocating scarce transmission resources per se. The question of who receives these funds will not hinder this allocation. As a practical matter, the funds collected could go to any entity or purpose as long as this disbursement would not create incentives that promote congestion. 


\section{FERC, NERC, and Regional Reliability Councils}

The Federal Energy Regulatory Commission (FERC), the North American Electric Reliability Council (NERC), and the NERC regional reliability councils all have oversight roles in managing congestion. FERC is primarily concerned with assuring fair and open markets while NERC and the regional councils focus on technical reliability issues. But reliability and markets are inexorably intertwined. "Technical" reliability rules inevitably impact markets and market incentives inevitably impact reliability. All three entities are evolving to try to deal with restructuring in general and transmission congestion specifically.

\subsection{FERC}

FERC has the national responsibility and authority to design the electric power industry structure. In order to remove impediments to the wholesale electric energy markets and to increase efficiency and reduce energy costs to consumers nationwide, FERC issued two Orders in April of 1996, which became the foundation for open transmission access. These orders apply to public utilities that own, control or operate facilities used for transmitting electric energy in interstate commerce. Order 888 requires these utilities to file open access non-discriminatory transmission tariffs. Order 889 requires the utilities to separate transmission and wholesale power merchant functions, and to participate in an Open Access Same-Time Information System (OASIS), which electronically provides all market players with transmission capacity, prices, and other information needed to obtain non-discriminatory open transmission access.

During the following three years, the industry underwent a sweeping restructuring under new federal and state regulations, including divestiture of generation plants by investor owned utilities, a significant number of mergers, and a large number of entrants such as power marketers and independent generation developers. Various independent system operators (ISOs) were established to manage large transmission systems. In December 1999, FERC issued Order 2000 to address transmission pricing, congestion, parallel path flow, planning, and coordination between regulatory agencies. Order 2000 compels the formation of Regional Transmission Organizations (RTOs), requiring all public utilities to be part of an RTO. Order 2000 also defines the minimum characteristics and functions of an RTO.

FERC recently adopted a more hands-on approach to achieve its goal of a seamless national power market place. FERC's role is to issue policy at the highest level, and it is still looking to country, state, and industry organizations to develop and implement reliability and business methods and standards. FERC is also active in bringing all stakeholders together to gain open communications between all and expeditiously coordinate the decision-making process. FERC's role is also to provide the needed authority to compel adherence to rules in the competitive power markets. 
FERC is focusing on six top priority items:

1. Congestion management

2. Cost recovery

3. Market monitoring

4. Transmission planning

5. Business and reliability standards

6. Transmission rights

Two main efforts are being pursued by FERC. One is to organize and form a limited number of RTOs nationwide to coordinate transmission activities over a broad geographic area. The second effort is to promote development of the necessary processes to make the market work, while meeting system reliability standards. The Commission feels that it needs to offer more direct guidance on key market issues than it gave in the past. This is in agreement with the industry's consensus that more complete and clearer interpretation of FERC's rules are needed to attain continuity in the market's operations between regions, which today have extremely diverse practices and procedures. To resolve this problem, FERC plans to initiate rulemaking activities on market design and structure to translate the eight RTO functions in Order 2000 into concrete protocols for the RTO organizations. A series of Commission-led workshops focused on each of the priority items listed. They are designed to result in a new pro forma tariff to replace Order 888 Open Access Transmission Tariff, and will be required of all public utilities and RTO's. This new tariff will favor market design standardization and will follow ongoing efforts by industry and state utility commissions. State regulators will be included in workshops on market design, particularly on the critical issues of cost recovery and market monitoring.

The following actions are also planned by FERC for implementation in the near term:

- All jurisdictional utilities must either elect to join an approved RTO or have all market-based privileges by any corporate affiliate be revoked.

- No mergers will be approved relating to entities that do not become part of an operational RTO.

- Public utilities who do not choose to be part of an RTO could be audited to ensure just and reasonable transmission rates.

- Pending rehearings and RTO filings will be expedited.

\subsection{NERC}

Historically, the vertically integrated utility industry utilized the North American Electric Reliability Council (NERC), a bottom-up, electric-utility-dominated, volunteer organization, to establish reliability rules and monitor compliance. NERC was formed in 1968 in the aftermath of the 1965 Northeast Blackout and in response to the 1967 U.S. Federal Power Commission report on that blackout recommending the formation of an industry-based national reliability organization. NERC is funded by the 10 regional councils, which adapt NERC rules to meet the needs of their regions (NERC 2001a). 
NERC and the regional councils have largely succeeded in maintaining a high degree of transmission-grid reliability throughout North America.

Until a few years ago, FERC and NERC operated on parallel tracks with little interaction needed between the two institutions. FERC oversaw bulk-power commerce, NERC oversaw bulk-power reliability, and there was little interaction between commerce and reliability. Unbundling generation from transmission and creating competitive markets for electricity are dramatically changing this situation. The industry now recognizes that reliability and commerce are tightly integrated. Increasingly, FERC receives cases in which market participants complain that NERC reliability rules, their implementation, or both competitively disadvantage them. NERC established a Market Interface Committee as a complement to its long-standing Operating and Planning Committees in September of 1998. NERC has been instrumental in making the congestion management issues visible and also in searching for solutions, which reconcile the reliability and physics of the grid with the developing competitive market needs. NERC spearheaded the OASIS Working Groups that developed the standards and communications protocols followed by all transmission providers to post market information and facilitate the Electronic Scheduling Collaborative, which recently filed a report with FERC on its efforts to develop common business practice standards for electronic scheduling (NERC 2001c).

In response to recent NERC requirements, Regional Security Coordinators coordinate within the reliability regions and across the regional boundaries. These security coordinators conduct day-ahead security analysis, analyze current-day operating conditions, and implement NERC's Transmission Loading Relief (TLR) procedures to mitigate transmission overloads.

Recognizing that curtailment is likely to occur when transmission capacity rights are granted at the same time to market participants and to power system operators, but based on totally different rules for each, NERC is promoting the development of a longterm plan to address the issues related to congestion management.

NERC is focusing on four priority issues associated with congestion management:

i. Reconciliation of economic and reliability management transmission models: When transmission reservations and schedules are made based on contract path models, and reliability assessment and transmission curtailment decisions are based on actual flows, the result is a challenge to integrate reliability and market needs. This issue could be mitigated through effective coordination of reliability impacts among providers during the reservation and scheduling assessment processes. However, on a tightly interconnected grid the coordination burden is high and, if not fully executed, can be frustrating to both the transmission providers and the market participants.

ii. Reduction of the proliferation of access rules and practices: Integration of market activities across regional and provider boundaries is challenged 
by the growing diversity of transmission access and congestion management procedures. While FERC regulations and the provincial Canadian regulatory authorities provide a foundation for transmission access and NERC policies establish a basis for reliability, regional entities and providers have sought and received approval for innovative tariffs. Regional scheduling and congestion management practices have provided integration and market efficiencies at the regional level but leave unanswered the challenge of integrating electricity markets at the North American level. FERC's RTO ruling does emphasize the need for interregional coordination. The question remains of how much integration and standardization is required to meet reliability and market objectives.

iii. Tool integration: A patchwork of tools is used for the market-reliability interface. FERC has required providers to offer reservations and ancillary services over OASIS. Scheduling and transaction tagging processes are handled on separate systems and congestion management on even other systems. Market participants have often expressed concern for the high transactional burden of dealing with so many different systems. Available systems appear to the market to be overly complex and redundant.

iv. Improvement of congestion management processes: The industry has not yet consistently met the market's needs for efficient and effective congestion management. Some concerns voiced include:

- The number and amount of transactions curtailed to solve a reliability constraint is excessive and costly to the market.

- There is limited opportunity or incentive to redispatch resources or take other actions to minimize reliability impacts on the market.

- There are limited incentives to the transmission provider to build transmission or otherwise remove transmission constraints.

- Market participants don't have access to timely and accurate information about transmission system constraints and congestion management actions.

Even though NERC is actively pursuing a market-oriented solution to congestion management, NERC's currently instituted and approved method is TLR, which is still curtailment-based, with some consideration given to non-discriminatory curtailment. In general, a transmission provider whose system becomes congested as a result of loop flows from transactions scheduled in other systems can use TLR to curtail the transactions creating congestion. With the substantial increase in wholesale transactions under FERC's directive of open access, a significant amount of interchange flows have been interrupted by TLR in order to maintain security. Hence, NERC issued its initiative to develop congestion management methods, which would mitigate the effects of TLR. 


\subsection{Regional Reliability Councils - WSCC as an Example}

The North American electric power system is divided into ten regions that are overseen by ten regional reliability councils (Figure 3.1). The councils are responsible for refining NERC reliability rules and applying them to the unique physical, commercial, and regulatory conditions of their region. Two of the councils are also interconnections, The Electric Reliability Council of Texas (ERCOT) and The Western Systems Coordinating

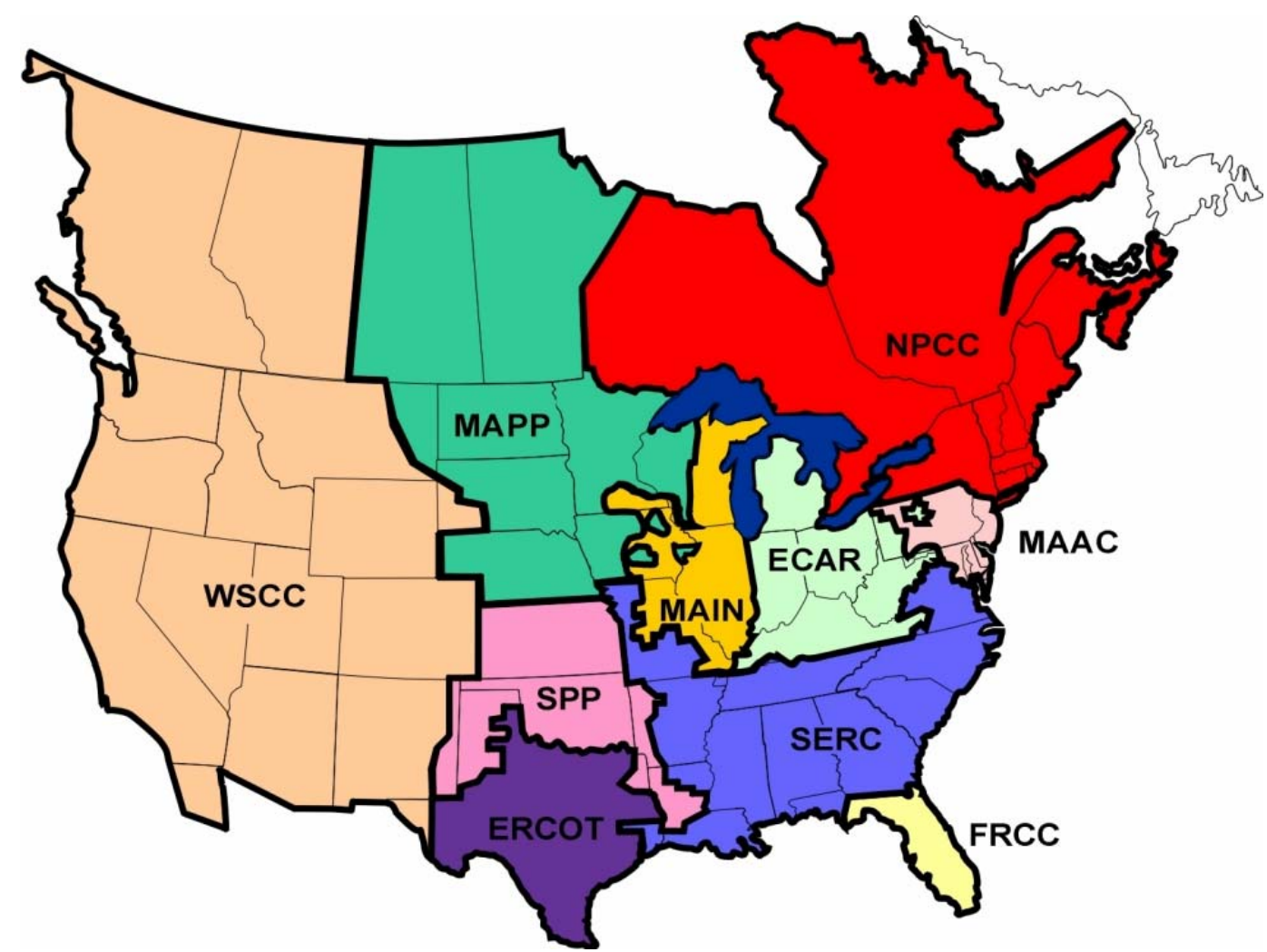

Fig. 3.1 NERC's 10 regional councils cover the 48 contiguous states, most of Canada, and a portion of Mexico.

Council (WSCC). These two councils and the Eastern Interconnection are connected to each other only through asynchronous DC ties. Two of the regions, ERCOT and Florida Reliability Coordinating Council (FRCC), are contained within a single state, Texas and Florida respectively. Two of these are also single control areas, ERCOT and MAAC (MAAC is also PJM). Three of the regions are international; Northeast Power Coordinating Council (NPCC), Mid-Continent Area Power Pool (MAPP) and WSCC have members in Canada as well as in the U.S., while WSCC also has members in Mexico. These are also historic entities where the current rules and regulations depend to a great extent upon the organizations past history. We examine one of these regional councils, WSCC, more closely to see how it deals with congestion management.

WSCC was formed with the signing of the WSCC Agreement on August 14, 1967 by 40 electric power systems. Those "charter members" represented the electric power 
systems engaged in bulk power generation and/or transmission serving all or part of the 14 Western States and British Columbia, Canada. Membership in WSCC is voluntary and open to major transmission utilities, transmission dependent utilities, and independent power producers/marketers. In addition, affiliate membership is available for power brokers, environmental organizations, state and federal regulatory agencies, and any organization having an interest in the reliability of interconnected system operation or coordinated planning.

The WSCC region encompasses a vast area of nearly 1.8 million square miles serving 65 million people with a peak load exceeding $130,000 \mathrm{MW}$. It is the largest and most diverse of the ten regional councils. WSCC's service territory extends from Canada to Mexico. It includes the provinces of Alberta and British Columbia, the northern portion of Baja California, Mexico, and all or portions of the 14 western states in between. Transmission lines span long distances connecting the Pacific Northwest with its abundant hydroelectric resources to the Southwest with its large coal-fired and nuclear resources. Figure 3.2 shows WSCC's dependence upon transmission links to integrate a large geographic area into a single interconnection. (WSCC 2001)

Historically, the reliability councils and NERC have functioned without external enforcement powers, depending on voluntary compliance with standards. Recognizing this, the "standards" were really only guidelines for good utility practice. NERC is now in the process of converting its system from one in which peer pressure encouraged compliance with voluntary standards into one in which compliance is mandatory and violations are subject to penalties (including fines). But the absence of federal legislation requiring compliance with reliability standards is problematic.

WSCC has taken a unique approach to compel compliance with reliability rules. WSCC members have voluntarily entered into binding contracts committing them to abide by WSCC reliability rules. WSCC is thus able to impose fines on many of the members if they fail to meet reliability standards. Contract law, rather than federal regulatory authority, provides the reliability incentive. The severity of the sanctions increase with seriousness and number of infractions.

WSCC's procedure to manage transmission congestion is based on the members' cooperation and results in stepped curtailments. This procedure was designed under the traditional vertically integrated electric utility industry structure. As such, it performed well for many years and met the requirements and expectations of all stakeholders in those times but it has difficulty coping with the new competitive environment. 


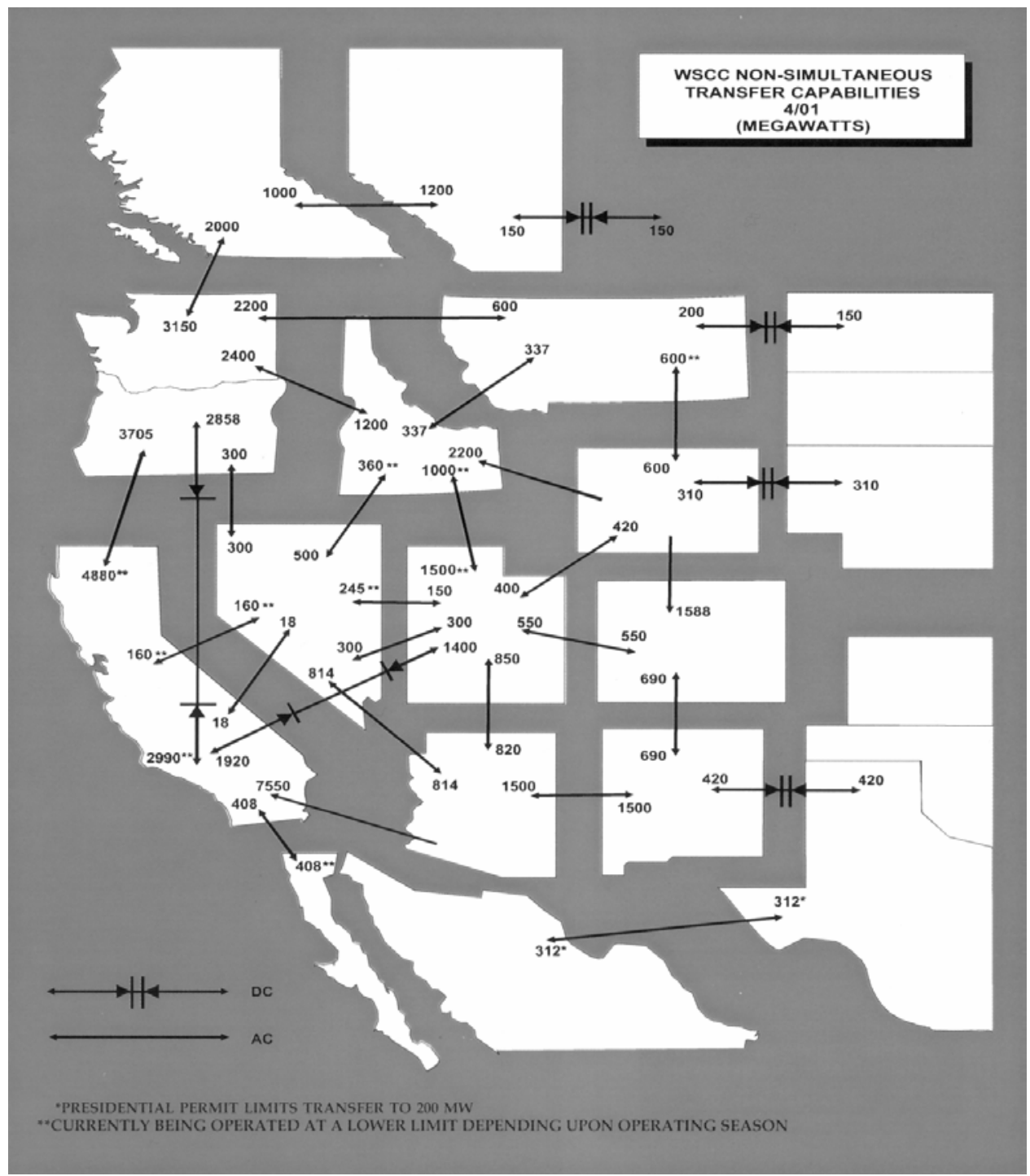

Fig. 3.2 WSCC congestion paths and flow limitations.

Table 3.1 summarizes the curtailment actions nine-step sequence, and is an example of scarce transmission capacity allocated on a system reliability basis. Transmission operators call for help whenever loading on their facilities becomes excessive. Relief actions can include adjusting phase shifters and other flow control devices, generation redispatch, and/or curtailment of transactions. The desired actions are implemented in the scheduling hour immediately following the request. Transmission operators are allowed to make an initial request for any step in the procedure up through the ninth step, provided that neither over-control nor over-curtailment are expected.

The transmission operator is typically only concerned with reducing the loading on the overloaded facility. Members may arrange among themselves to make different 
curtailments than those specified by the transmission SO as long as they are equally effective in alleviating the overload condition. Providing for alternative arrangements that members arrive at themselves is the beginnings of a market response to congestion and can greatly increase the economic efficiency of congestion management.

If the constraint persists, then each successive step is taken until the desired relief is obtained. The transmission system operator must reconfirm the need to continue the curtailments at least every four hours. The transmission SO must also notify members that curtailments can be reduced when the actual flow on the facility of concern is reduced below 97 percent of its transfer limit. Schedules are resumed in the reverse order that schedule curtailments were initiated.

Table 3.2 compares the FERC, NERC and WSCC requirements for congestion management. All three organizations have traditionally worked closely, but due to the basic differences in their respective roles, their functions are different. FERC is a highlevel policy maker, while WSCC is closer to the day-to-day operations, with NERC in the middle of the spectrum. This is reflected in the table in the degree of detail with which each organization has addressed congestion management requirements.

The voluntary cooperation which existed at the regional level (WSCC) and that allowed efficient management of unscheduled flows in the vertically integrated past is now being replaced with mandatory coordination starting at the national (FERC) and inter-regional (NERC) levels to support competitive markets. This is a direct consequence of the number and diversity of participants in the market with a wide range of objectives. 


\section{WSCC UNSCHEDULED FLOW PROCEDURE SUMMARY OF CURTAILMENT ACTIONS}

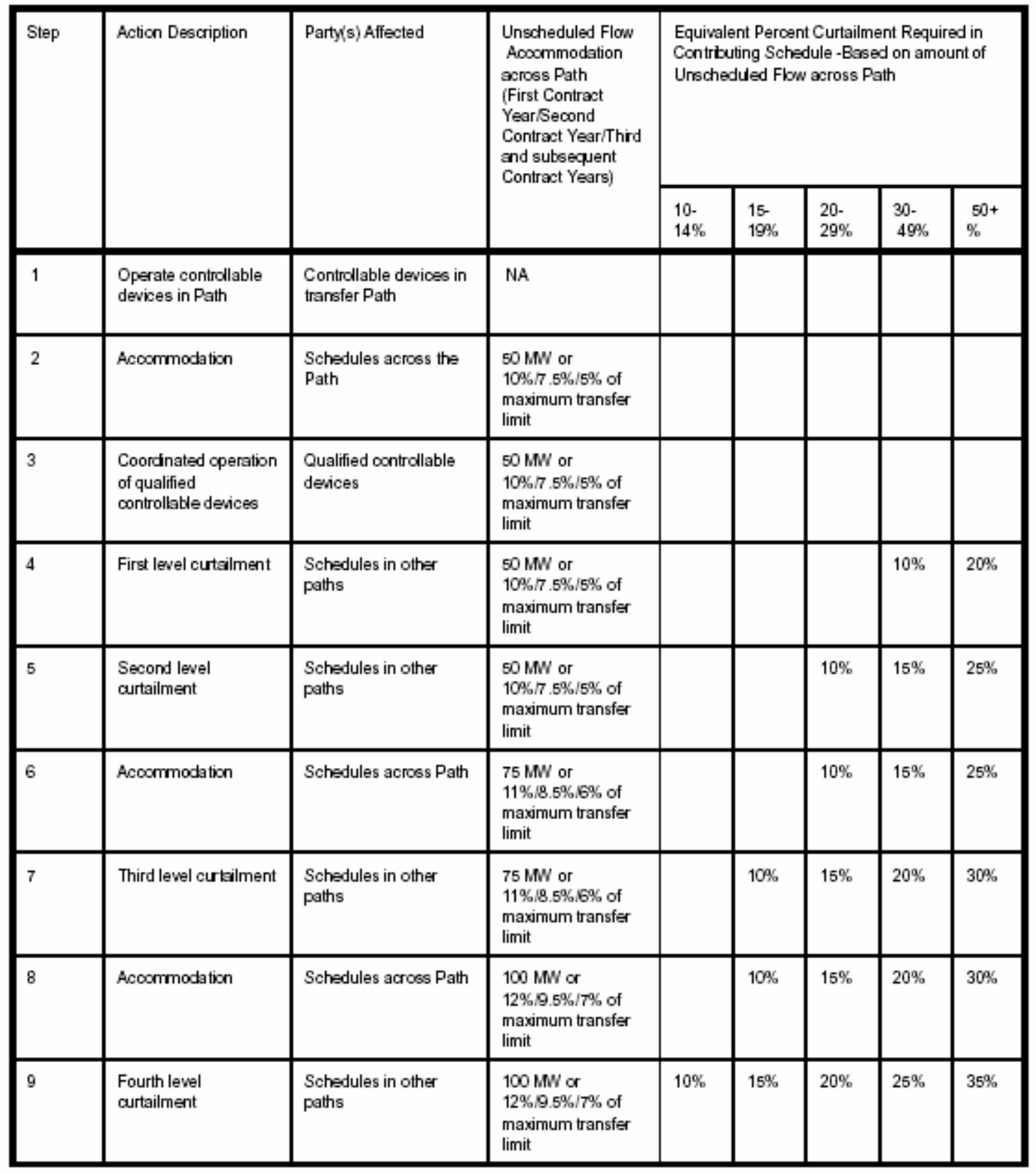

Table 3.1 WSCC utilizes a nine step reliability-based process for transmission system operators to obtain relief when their facilities are overloaded 


\begin{tabular}{|c|c|c|c|}
\hline $\begin{array}{l}\text { ENTITY } \\
\text { ATTRIBUTES }\end{array}$ & FERC & NERC & WSCC \\
\hline \multicolumn{4}{|l|}{$\begin{array}{l}\text { Implementation and } \\
\text { Performance }\end{array}$} \\
\hline $\begin{array}{l}\text { - Congestion } \\
\text { Management } \\
\text { Effectiveness }\end{array}$ & $\begin{array}{l}\text { FERC recognizes transmission } \\
\text { congestion as the highest priority } \\
\text { issue, however Order } 2000 \text { only } \\
\text { discusses this in broad terms and lists } \\
\text { comments from future market } \\
\text { participants. }\end{array}$ & $\begin{array}{l}\text { After FERC } 888 \text { and } 889 \text { rulings, NERC } \\
\text { recognized impact of own Transmission } \\
\text { Loading Relief method on market development. } \\
\text { Now promoting new CM methods to mitigate } \\
\text { TLR effects (Policy 9). }\end{array}$ & $\begin{array}{l}\text { Curtailment and redispatch highly effective CM before } \\
\text { deregulation, due to close cooperation among WSCC } \\
\text { members and strict adherence to normal and emergency } \\
\text { reserve margins. Minimum cooperation and margins today. }\end{array}$ \\
\hline $\begin{array}{l}\text { - Interregional } \\
\text { Coordination }\end{array}$ & $\begin{array}{l}\text { FERC's thrust has been to have } \\
\text { utilities voluntarily form regional } \\
\text { transmission organization (RTO's) } \\
\text { nationwide. Recently FERC has stated } \\
\text { this requirement more forcefully. }\end{array}$ & $\begin{array}{l}\text { Compliance with NERC guidelines is mandatory } \\
\text { but not enforceable. NERC is transitioning to } \\
\text { NAERO to gain legislation and enforce } \\
\text { nationwide. }\end{array}$ & $\begin{array}{l}\text { Voluntary compliance with WSCC guidelines is now low. } \\
\text { Some new market participants are not members. New } \\
\text { organization for western interconnected states being } \\
\text { proposed. }\end{array}$ \\
\hline - Transactional Burden & $\begin{array}{l}\text { FERC, NERC, and others 'councils' } \\
\text { provide mandates only, and leave } \\
\text { implementation to users, hence } \\
\text { burden depends on users' selection of } \\
\text { a specific approach. }\end{array}$ & $\begin{array}{l}\text { Implementation details are left to RTO's, ISO's } \\
\text { and state regulators. }\end{array}$ & WSCC reporting and accounting was considered reasonable. \\
\hline \multicolumn{4}{|l|}{ Market Impact } \\
\hline - Cost Allocation Equity & 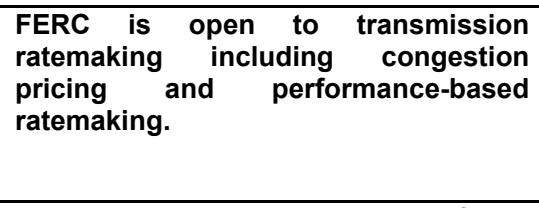 & $\begin{array}{l}\text { Under TLR, transmission capacity allocated on } \\
\text { reliability basis, with some non-discriminatory } \\
\text { provisions. Can result in service disruptions } \\
\text { and high monetary penalties. NERC is } \\
\text { supporting a Locational Margin Pricing pilot } \\
\text { and redispatch studies to upgrade from TLR. }\end{array}$ & $\begin{array}{l}\text { Some adjustments were made to local utilities, after the fact, } \\
\text { due to redispatch and loop flows. }\end{array}$ \\
\hline - Implementation Costs & $\begin{array}{l}\text { Implementation details are left to } \\
\text { RTO's, ISO's and state regulators. }\end{array}$ & $\begin{array}{l}\text { Minimum for TLR because this is an } \\
\text { established method. OASIS is an on-line } \\
\text { available transfer capability reporting system } \\
\text { made mandatory by NERC. }\end{array}$ & $\begin{array}{l}\text { Implementation cost was generally spread over all loads } \\
\text { within a local system. }\end{array}$ \\
\hline - Investment Incentives & Case-by-case incentive pricing. & $\begin{array}{l}\text { Weak signals given by TLR to invest in either } \\
\text { generation or transmission. }\end{array}$ & $\begin{array}{l}\text { No special investment signals. Public utility commissions } \\
\text { mandate new installations. }\end{array}$ \\
\hline $\begin{array}{l}\text { - Forward Markets } \\
\text { Support }\end{array}$ & $\begin{array}{l}\text { FERC favors } \text { market } \quad \text { design } \\
\text { standardization. On-line market } \\
\text { information system (OASIS) with } \\
\text { access to all market participants was } \\
\text { sponsored by FERC. }\end{array}$ & $\begin{array}{l}\text { TLR does not support well real-time, high } \\
\text { trading volume, or energy market pricing. }\end{array}$ & $\begin{array}{l}\text { Forward markets were stable and did not require price } \\
\text { variations to exist. }\end{array}$ \\
\hline $\begin{array}{l}\text { Retail Market } \\
\text { Compatibility }\end{array}$ & $\begin{array}{l}\text { Only generation and the bulk } \\
\text { transmission system have been } \\
\text { addressed so far. Retail does not } \\
\text { appear in FERC's five-year plan. }\end{array}$ & $\begin{array}{l}\text { TLR focuses on the bulk power market, with no } \\
\text { built-in considerations for retail transaction by } \\
\text { all users. }\end{array}$ & Not Applicable. \\
\hline
\end{tabular}

Table 3.2 Congestion management requirements comparison 


\section{ISO CONGESTION MANAGEMENT}

ISOs put the guidance provided by FERC, NERC, and the regional councils into practice. They deal with physical systems and real markets. They are responsible for real-time operations and have the ultimate responsibility for bulk power system reliability. The approaches taken by individual ISOs differ because of differences in their physical systems (geographic layout, generation mix, etc.) as well as historical differences in how they were formed. None of the ISOs have finished developing their congestion management procedures; all are still trying to develop better systems. This chapter examines three ISOs in some detail (ERCOT, California, and PJM) to see the differences in how they deal with congestion management. Naturally, the specific rules that govern precise requirements in each ISO are quite detailed. We intentionally provide a more generalized summary here to avoid losing sight of the important concepts in the specific implementation details.

\subsection{Electric Reliability Council of Texas}

The ERCOT is unique in that it is an interconnection, a NERC region, and an ISO. ERCOT serves approximately 85 percent of the state's electric load (Figure 4.1) and oversees the operation of approximately 70,000 megawatts of generation and over 37,000 miles of transmission lines. The ERCOT interconnection is contained completely within the borders of Texas, and it doesn't interconnect synchronously across state lines to import or export power with neighboring states. As a result, ERCOT is not under FERC's jurisdiction. ERCOT is the only ISO in the 48 contiguous states that is under the jurisdiction of a single public utility commission. ERCOT membership consists of six Cooperative generation and transmission utilities and River Authorities, six Municipals owning generation or transmission, four Investor-owned utilities, fourteen Independent Power Producers, twenty-three Power Marketers, fourteen Transmission-dependent utilities, and Retail Consumer representatives. ERCOT's organizational structure includes a Board of Directors, Technical Advisory Committee, three standing subcommittees (Engineering, Reliability and Security, and Transmission Market Operations), and a number of task forces and working groups. Historically, ERCOT's role as a regional reliability council was to maintain the reliability of the bulk power system in Texas. As an ISO, ERCOT is now also responsible for providing a fair and open market place for wholesale and retail competition. (ERCOT 2001a)

ERCOT employs a flow-based/zonal approach to manage forward markets and congestion. A set of commercially significant constraints or 'flow gates' is selected. Transmission service is reserved through OASIS. The ERCOT ISO considers requests on a first-come first-served basis. Available transfer capability is considered together with ancillary service requirements. Notification is given to market participants of the evaluation of their requests according to the following schedule:

- Within 10 minutes of the request for hourly transactions;

- Within four hours of the request for daily transactions; 


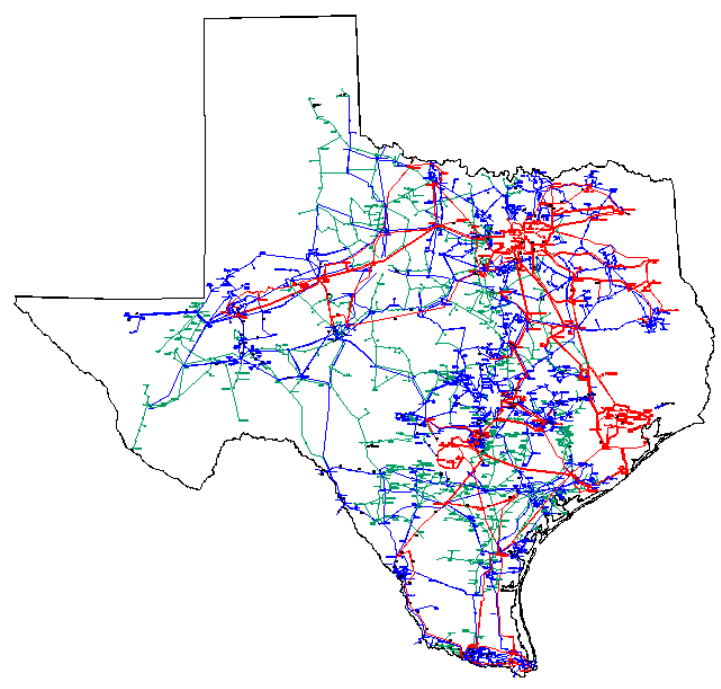

Fig. 4.1 ERCOT serves approximately $85 \%$ of the Texas load

- Within 24 hours of the request for weekly transactions; and

- Within two days of the request for monthly transactions.

Necessary actions are taken to ensure reliability whenever transmission capacity is insufficient to meet the scheduled transactions. Redispatching of generation is used to manage congestion and ERCOT requests the market to provide prices for generation redispatch. Generation is increased (and decreased) in economic order. Other actions taken could include transaction cancellations, rescheduling of planned transmission service, scheduling new transactions to offset an impacting transaction, and rescheduling transmission line maintenance. (ERCOT 2001b, ERCOT 2001c)

\subsubsection{Defining Congestion Zones}

ERCOT uses a flow-based zonal congestion management scheme. The zones are defined such that each generator or load within the zone has a similar effect on the loading of the transmission lines between zones. Once zones are defined, any imbalance between load and generation within a zone is assumed to have the same impact on inter-zonal congestion. Zone boundaries are reexamined annually to see if generation, load, or transmission patterns have changed enough to warrant changing the zones. The zones are designed to capture the "commercially significant constraints".

ERCOT performs a technical analysis of the system by October of each year to determine expected transmission system operating limits and constraints. This analysis considers transmission system additions and retirements as well as changes in load and generation patterns (Fig. 4.1.1.). An advisory committee then analyzes the list of constraints and determines which are "commercially significant". The committee considers historic and expected congestion costs when determining which constraints are commercially significant. Costs include the cost of reliability-must-run units and outof-merit-order operations of other generators needed to resolve congestion. (ERCOT 2001f) 
A DC load flow model is used to determine the impact of load or generation changes at each buss (location) in the ERCOT system on each of the commercially significant congestion paths. Statistical clustering is then used to aggregate transmission busses into congestion zones based upon their having similar impacts on the congestion paths.

A stakeholder process is used to determine the number of zones (ERCOT 2001d). The process attempts to balance the competing goals of minimizing the number of congestion zones while still accurately capturing the impact each load and generator has on congestion. ERCOT currently has 3 congestion zones. As of December 2001, there were only two commercially significant congestion paths connecting these three zones; north/south and north/west. Table 4.1.1 shows the annual MW capacity of each path.

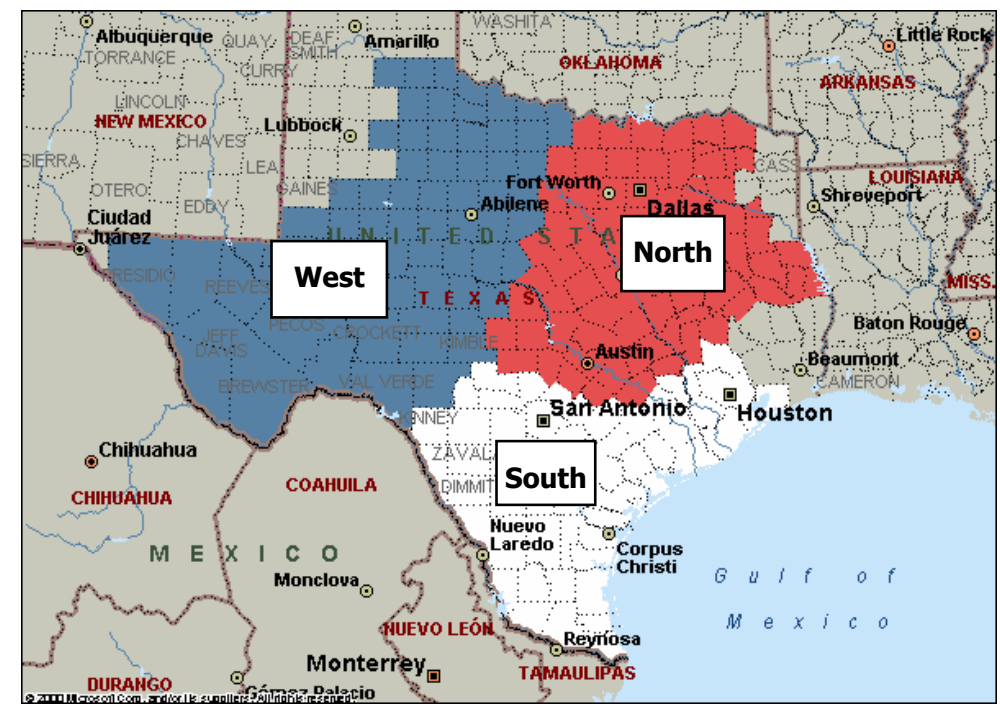

Fig. 4.1.1 ERCOT currently has 3 commercially significant congestion zones

Table 4.1.1 also shows how much impact a change in generation or load in any of the congestion zones has on each of the congestion paths. These "zonal shift factors" are calculated by taking the weighted average of the impacts of each load and each generator within the zone on each congestion path. These averages are weighted based upon peak loads and generator maximum ratings and are established annually. The zonal shift factors are used in calculating congestion rates to be charged for creating congestion. 


\begin{tabular}{ccccc}
\hline Congestion Path & N / S & S / N & N / W & W / N \\
\hline Transfer Capability (MW) & 3262 & 1124 & 2104 & 2000 \\
\hline Congestion Zone & $\begin{array}{c}\text { Impact of a change in load or } \\
\text { generation on a congestion path }\end{array}$ \\
North & $24.9 \%$ & $2.6 \%$ \\
South & $3.4 \%$ & $0.9 \%$ \\
West & $22.2 \%$ & $54.6 \%$ \\
\hline
\end{tabular}

Table 4.1.1 ERCOT December 2001 analyses showed 3 congestion zones and two congestion paths

\subsubsection{Managing Congestion}

Day ahead and operating schedules are analyzed by the ERCOT ISO to determine if inter-zonal congestion is expected. Market participants are notified of the congestion expectations in order to allow them to adjust their schedules and reduce congestion. The ERCOT ISO then purchases replacement reserve service and gets bids for balancing energy capacity to manage the remaining congestion. Balancing energy resources are dispatched in economic order to minimize the cost of mitigating congestion. Reliability-must-run and out-of-merit-order generation is used for congestion management only in the absence of market-based solutions, but they are available if the ISO believes they are needed.

\subsubsection{Charging for Congestion}

Market participants are charged for inter-zonal congestion based upon an average annual congestion price (per MWH) for each congestion path multiplied by their current impact (MW) upon each congested path and the duration of the congestion ( $\mathrm{Hr}$ ). The use of annual average prices rather than real-time costs makes it easier for market participants to know how much congestion will cost them ahead of time. Unfortunately, it also means that the ISO may not collect enough revenue to cover the cost of congestion mitigation. Additional costs that are not covered by the use of the annual average rates are allocated to all customers on a pro-rata basis.

Intra-zonal congestion is identified by a local congestion management model based upon market participants hourly generation and consumption schedules along with an ISO estimate of the expected load. The ISO then procures appropriately located replacement reserves to relieve the expected congestion. Markets are used to obtain balancing energy to relieve congestion whenever possible. The cost of intra-zonal congestion is also allocated to all customers on a pro-rata share (postage-stamp rate) rather than charged directly to the party causing the congestion. 


\subsubsection{Congestion Management Improvements}

ERCOT plans to start charging customers directly for the commercially significant congestion they cause by 2004 , or sooner if the cost of congestion reaches $\$ 20$ million. ERCOT will then directly charge market participants for the replacement reserves it must procure each hour to accommodate energy imbalances and congestion based upon their hourly contribution to that need.

ERCOT also plans to initiate the use of transmission congestion rights (TCRs) when direct charging for congestion is instituted. TCRs function as financial hedges against high congestion costs. ERCOT will determine the amount of TCRs available by modeling the system. Sixty percent of the available TCRs for each congestion path for each hour of the year will be auctioned off to market participants annually. The remaining fourty percent of the hourly TCRs will be auctioned off monthly. ${ }^{2}$ The full capacity of the congestion paths will be used; there will be no reservation of capacity for any particular segment of load.

\subsubsection{Transmission Expansion}

ERCOT reviews the cost of correcting localized transmission limitations through new construction or other means, and compares this to the costs incurred to correct those problems. If the projected or actual cost of congestion management is greater than the cost of correcting the transmission limitations through construction of facilities, then ERCOT may recommend an upgrade of facilities to the transmission owner.

\subsection{California ISO}

California was the first state in the nation to offer large-scale retail choice and a competitive generation market. To facilitate this state legislation passed in 1996 required the three investor-owned utilities in the state (Pacific Gas and Electric, Southern California Edison, and San Diego Gas and Electric) to turn over control (but not ownership) of the transmission system to the new, not-for-profit, California ISO. ISO operations began on March 31, 1998.

The California ISO's power system covers 124,000 square miles, about $75 \%$ of the state. It supports a $\$ 21$ billion/year electric energy industry and supplies 164 billionkilowatt hours and 45,000 peak megawatts of electricity to 27 million customers through 25,000 circuit miles of transmission lines each year. The generation resource mix is diverse with hydro, nuclear, fossil thermal, geothermal, pumped storage, gas turbines, cogeneration, wind and solar power plants all participating. California imports $20 \%$ of its electric energy needs. It is the second largest control area in the U.S. (PJM is the largest) and the fifth largest in the world. The ISO built two new control centers, a main control center in Folsom and a backup control center in Alhambra. The California ISO is

\footnotetext{
${ }^{2}$ Market participants that own remote generation or that have long term contracts with remote generation (established prior to September 1999) will have pre-assigned TCRs.
} 
a member of WSCC and one of WSCC's four regional security coordinators. (California ISO, 2001a)

The mission of the California ISO is to ensure safe and reliable operation of the transmission system and control area and that there is a competitive market for electricity in California. It is specifically charged to rely on market solutions whenever possible, taking direct action only after trying market solutions. ${ }^{3}$ It also fosters market friendly reliability standards within NERC, WSCC, and FERC. The ISO recognizes that the markets are developing and seeks to continuously improve market rules utilizing a stakeholder process to build consensus. (California ISO 1998)

The California transmission system can become constrained for a number of reasons. Stability limits, thermal limits, water management, and fuel availability (gas) are all important contributors at different times. With a high dependence upon imported electricity, constraints on interfaces to the Pacific Northwest, Arizona, and Nevada are all important. (Alaywan 2001)

The California ISO uses a hybrid zone-based approach to manage congestion. As in the case of ERCOT, a zone is part of the ISO-controlled area within which congestion occurs infrequently. However, inter-zonal boundaries have relatively high congestion and associated congestion management costs. At these boundaries, allocation of usage is based on the value assigned to these boundaries by the scheduling coordinators. The purpose of this is to increase efficiency in the use of the transmission system. Congestion charges account for about $10 \%$ of the ISO market costs, which themselves account for approximately $12 \%$ of the retail electricity cost. (California ISO, 2001b)

\subsubsection{Defining Congestion Zones}

Congestion zones, and the paths that connect them, are redefined annually. For 2002 the ISO has established three internal zones (NP15, SP15, and ZP26) and nine external zones (2 in the Pacific Northwest, Nevada, 2 in Arizona, the Lower Colorado, Imperial Valley, Los Angeles, and Mexico) that have distinct and commercially significant congestion. There are nineteen paths connecting these zones. The configuration can be seen in Figure 4.2.1. Zones are defined based upon technical analysis and the expectation of congestion between the zones. The California ISO Board approves the zonal definitions; the process of defining zones is not exclusively technical. (McClain, 2001)

\footnotetext{
${ }^{3}$ ISO actions are subject to reliability, safety, environmental, and future market impact constraints.
} 


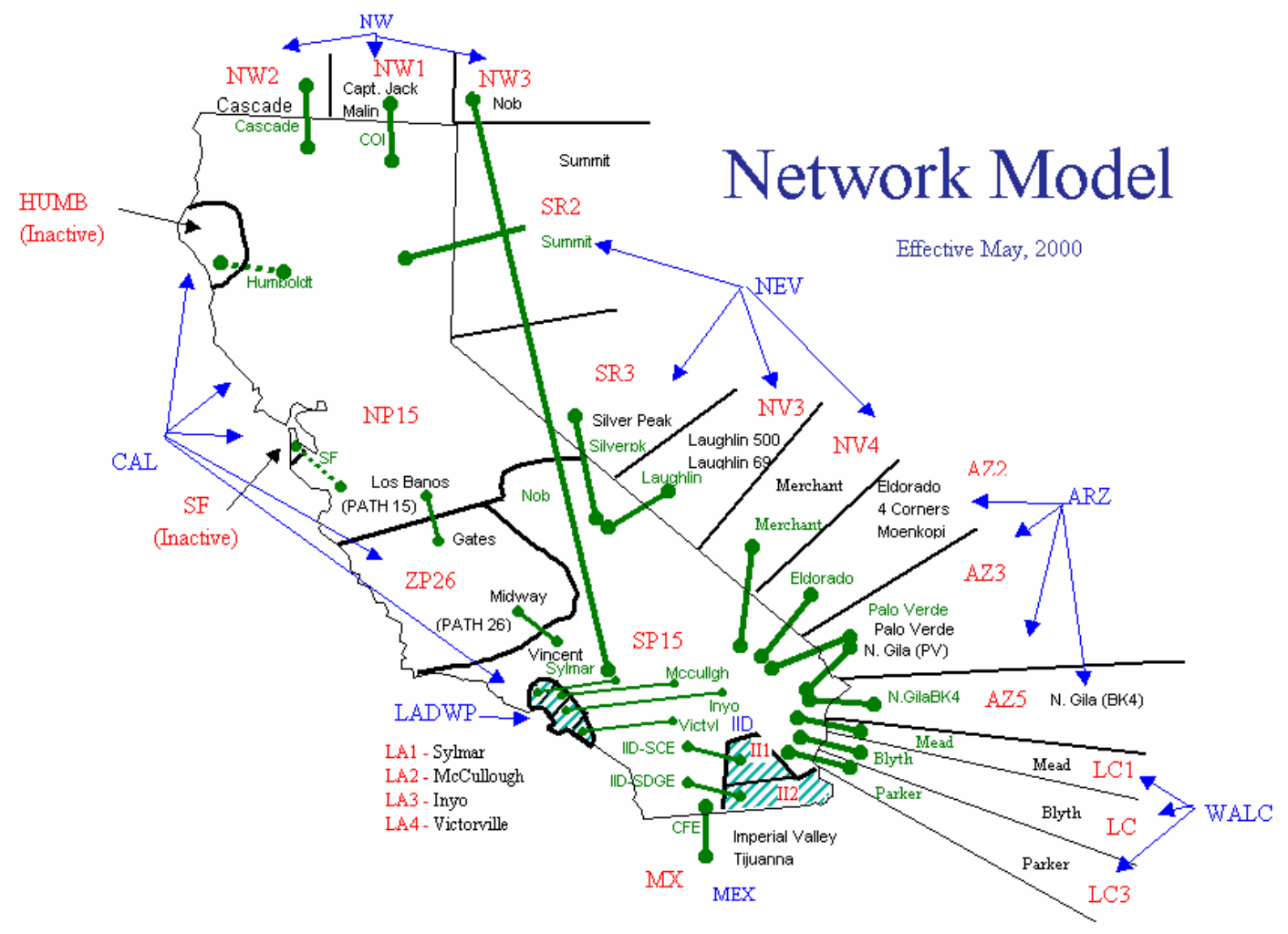

Fig. 4.2.1 The California ISO's transmission system serves approximately $75 \%$ of the state and consists of three internal congestion zones connecting to nine external zones. (www.caiso.com)

\subsubsection{Managing Congestion}

Inter-zonal congestion management is performed for the overall network with the objective of minimizing congestion costs. Market participant's portfolios are not optimized within zones by the ISO. The California ISO relies heavily on markets to supply customers' energy requirements and to manage congestion. Market participants (scheduling coordinators, in California) are required to balance their own supply and demand schedules. The ISO uses the real-time imbalance market to accommodate the inevitable differences between schedules and actual production and consumption. The ISO also uses ancillary service markets to obtain regulation and reserve resources.

The ISO analyzes the initial schedules submitted by the market participants to see if transmission limits will be violated. If the ISO sees that the proposed energy schedules will result in transmission congestion the ISO utilizes "adjustment bids" that were also submitted by the market participants to adjust schedules and alleviate the congestion. The adjustment bids are obtained from a congestion management market run by the ISO where market participants submit bids in day-ahead and hour-ahead markets that reflect the market participant's price for deviating (up and down) from the submitted schedule. Market participants that do not provide adjustment bids do not have their schedules adjusted and become congestion price takers. (Lo, Xie, Senthil, Alaywan and Rothleder, 2001) 
Inter-zonal congestion management in California keeps each market participant's portfolio of generation and load resources separate. The ISO does not pay for adjustment energy. The ISO's redispatch to alleviate inter-zonal congestion increases output from one of the market participant's generators (or reduces load) while it decreases output from another of the same market participant's generators on the opposite ends of a congested path by the same amount. Thus the ISO is buying transmission capacity, not energy, and the congestion mitigation scheme determines the marginal cost of congestion mitigation. The ISO avoids interfering in the forward energy markets by keeping each market participant's portfolio of generation and load separated and in balance. (Alaywan 1999)

If the market participants do not voluntarily eliminate congestion, CAISO may order generation plants that have not submitted bids to bid, if their generation is necessary to reduce congestion. These plants are paid at real-time energy prices determined by the market. CAISO also has the authority to readjust market participant's schedules and eliminate trades.

A special congestion management procedure to reduce the number of real time schedule adjustments and enhance reliability has been established for the CaliforniaOregon Intertie. This intertie consists of three parallel $500 \mathrm{kV} \mathrm{AC} \mathrm{lines,} \mathrm{which} \mathrm{can}$ experience unscheduled flows when hydro is plentiful in the Northwest and demand is high in California. The ISO determines the historical amount of unscheduled flow on the intertie by reviewing data from similar days and estimates the amount of expected unscheduled flow. The amount of capacity made available to the market on the California-Oregon Intertie is then reduced to a level deemed reasonable to meet reliability criteria. Market participants are notified of the reduced capacity.

\section{Intra-zonal Congestion}

Congestion can also occur within the zones. Early market rules constrained the ISO's ability to deal with intra-zonal congestion. It was forced to pay very high adjustment bids to resolve intra-zonal congestion, even when significantly lower energy bids were available for the same capacity, or even when outside resources with lower bids were available to resolve the congestion problem. At one time, the cost of this inefficiency amounted to $\$ 750,000$ per day.

California ISO now relies first on market bids in their real-time management of intrazonal congestion. Congestion is resolved in each zone separately. The objective is to minimize the economic shift among market participants. Bids remaining after the dayahead and hour-ahead energy markets and real-time imbalance energy bids are used. Incremented and decremented bids on either side of the congested interface are exercised in pairs to relieve the congestion based upon their effectiveness and in merit order. Intra-zonal congestion management is implemented so as not to inadvertently create inter-zonal congestion. The difference in incremental and decremental bids is the intra-zonal congestion charge. Market participants are notified at the end of each hour 
what range in bid cost was required to control intra-zonal congestion over the course of the last hour.

In the event that intra-zonal congestion cannot be mitigated with market solutions, the ISO has several other tools available. Reliability must-run resources and out-of-market calls can be used. Energy schedules can be adjusted on the Pacific Direct Current Intertie and/or the California-Oregon Intertie. Costs associated with changing schedules and flows on the AC and DC ties, such as losses and wheeling costs, are paid by the ISO and recovered from the market participants.

\subsubsection{Charging for Congestion}

Fixed transmission costs are recovered from loads through usage-based transmission rates. With fixed transmission costs covered, the ISO is able to price incremental transmission use at the marginal cost for removing congestion. The ISO's marginal cost for alleviating congestion is based upon the adjustment bids that the ISO has to exercise to counteract the congestion. Users pay nothing when there is no congestion and they pay the full marginal cost when there is congestion. This sends the correct economic signal to the market to efficiently allocate scarce transmission resources. It also introduces price volatility and price risk. (Alaywan 1999)

FTRs can help transmission customers reduce the price risk and volatility associated with congestion management. The California ISO auctions limited-term FTRs annually that have both financial and physical attributes. FTRs are initially auctioned for a full year but can be traded hourly in the secondary market. FTRs are available for 19 congestion paths connecting 3 internal and 9 external congestion zones.

FTRs provide the owner with income and preferential scheduling from congested interfaces. A market participant that owns FTRs equal to (same congestion path, same direction, and same number of MW) a transmission schedule that the market participant is trying to execute is immune to congestion pricing because the FTRs provide income equal to the transmission congestion charge that market participant has to pay.

FTR owners are also last to have their schedules curtailed if market mechanisms are not sufficient to manage congestion. This provides physical assurance that specific generation can be scheduled to a specific load. This does not allow FTR owners to withhold transmission capacity from the market. If the FTR owner does not use the capacity, the FTR owner looses the scheduling priority. The FTR owner still gets any revenue associated with the FTR.

The ISO first auctioned FTRs for 19 congestion paths in November of 1999 selling about one third of the available transfer capability. The revenue collected by the ISO when FTRs are auctioned is given to the transmission owners to offset fixed transmission costs. This, in turn, reduces the transmission rate paid by all transmission 
customers. It is important that neither the transmission owner nor the ISO profit from the sale of FTRs or it would provide them with an incentive to create congestion. ${ }^{4}$

\subsubsection{Congestion Management Improvements}

Recently, the California ISO, together with the principal market players, has begun to restructure the congestion management process due to the results experienced over the last three years. The objective of this ongoing effort is to improve the clarity of price signals to the markets (locational accuracy and strong indicators for new installation investments). Four deficiencies are being addressed for correction, which should bring the market closer in-line with FERC's requirements:

1) Forward schedules that are not feasible and could be used to manipulate prices are to be eliminated.

2) Accuracy of locational price signals is to be improved.

3) Abuse of locational market power is to be eliminated.

4) Complete and timely operational information for market participants is to be improved.

The last point is critical to achieve reliable system operation that also supports a competitive real-time market. To implement real-time operation, the proposed approach focuses on making visible to the market all operating practices and procedures, and on defining locational pricing on an operational basis and consistent with established reliability criteria. This requires the redefinition of locational price zones and FTRs to better reflect both how the system is managed and how the market conducts transactions in real-time.

CAISO plans to increase the number of congestion zones in order to improve the accuracy of locational price signals. The definition of zones will be based on the engineering requirements, system conditions, and criteria/practices that guide real-time operation to ensure grid reliability, as opposed to today's approach for revising zonal boundaries based on intra-zonal congestion costs. Based on existing operating practices and management's current assessment of engineering considerations, the ISO will initially define 11 congestion zones, adding 8 new zones to the 3 existing zones. As further engineering studies are conducted, the ISO may revise this list, and will bring any revisions before the CAISO board. The ISO will publish information to the market, including the grid operating procedures and nomograms used by operators to ensure real-time reliability. Related information including current system conditions, load forecasts, and the energy and capacity that will be needed in real time for local reliability in each congestion zone will also be published.

To manage forward congestion across the inter-zonal interfaces, the ISO will use an optimization program in conjunction with the commercial network model to dispatch resources, simultaneously balancing demand and supply and managing real-time

\footnotetext{
${ }^{4}$ One exception involves new facilities. Whomever pays for new transmission facilities receives the auction revenue when the FTRs associated with the added capacity are auctioned. It is hoped that this will encourage new transmission investment.
} 
congestion. The optimization program will determine every ten minutes the optimal dispatch of participating resources, taking into account resource capability (e.g., ramp rates) as well as inter-zonal transmission constraints. Market participants will be required to schedule generation at the buss level, as they do today. Loads may be scheduled at the buss or the zonal level.

The congestion iteration of the current day-ahead market will be retained. Adjustment bids that are not used in the first iteration will be published on a voluntary basis, to facilitate market participant trading to relieve congestion. The first or second iteration will be selected as the final schedule, depending on which had lower total inter-zonal congestion costs. Ancillary services will not be procured at the zonal level, but only system-wide or within competitive congestion regions (i.e., what are today's three active zones).

Following the running of the usual congestion management for firm schedules, the ISO will run a market for recallable transmission service in order to obtain additional resources for dealing with congestion. The ISO will obtain forward commitments of resources needed for local reliability primarily through local reliability service procurement for each zone. Three alternatives have been proposed on the method of obtaining reliability resource commitments: two-day ahead procurement, long-term contracts, and adjustment bids using the congestion management software. The ISO will retain a contract option similar to today's reliability must-run contracts that can be elected from those resources needed for local reliability that would not otherwise be viable in the markets.

The ISO will define the minimum reliability capacity and energy required for each congestion zone (and sometimes from specific generators) based on forecasts of load and system conditions. Each market participant that serves load will have to supply both energy and capacity to fulfill this requirement:

- Minimum Reliability Energy - energy that must be scheduled in the forward markets against load in the relevant zone, as part of a market participant's balanced schedule;

- Contingency Capacity - additional capacity that must be available for dispatch in real time; the capacity does not have to be unloaded like typical reserve capacity, but may be forward scheduled or bid into the ancillary services or supplemental energy markets.

The ISO will pay for the required capacity if it is not being sold into the ancillary service or other markets. The ISO will pay for the Minimum Required Energy; it must be scheduled into the energy markets. The ISO will pay for energy dispatched in real-time out of the Contingency Capacity.

An auction will be conducted to procure this zonal reliability energy and capacity to encourage providers to bid competitively. If competition is not feasible in a zone, bids will be capped to mitigate market power. The bid caps could be set just high enough to 
cover the cost to provide the services. Alternatively, the bid caps could be set higher to provide incentives for new resources to locate within the congested zone. Alternatives to the bid cap structures are that the bid cap be: zone-specific, resource-specific, or constant across the ISO area.

All resources will be required to participate in the zonal reliability energy and capacity auctions. Default bids will be used if the resource does not submit a bid. Substantial penalties will be imposed on resources that sell capacity and then fail to schedule energy in the forward markets or fail to deliver energy or capacity in real-time. Provision will be made to exempt resources from these penalties under force majeure conditions and to perform necessary scheduled maintenance.

The cost of the zonal reliability procurement will be allocated initially based on the loads within each participating transmission operator's service area. Over five years this will shift towards allocation based on loads within each zone.

As part of its ongoing monitoring to evaluate system performance and to assess whether zonal boundaries or other features of the commercial network model need to be modified, the ISO will run a full internal network model (3000 busses), utilizing all actual constraints in the system.

To help mitigate transmission price volatility and to reduce the risk of curtailment due to transmission congestion the use of FTRs will be refined in the future market structure. All of the available transfer capability will be auctioned off as FTRs. Initially, a one-year auction will release half of the available capacity. A monthly auction will release all remaining capacity that is available all month based upon the minimum hourly transmission capacity available for the month. The remaining transmission capacity will be allocated in the new firm uses market. Revenues from FTRs auctions may be allocated to the transmission owners as is done today. Alternatively, these revenues may be allocated to a path-specific transmission upgrade fund.

One area of contention in improving the congestion management scheme is that some market participants want more than engineering criteria to be used in defining congestion zones, and they would like to see this done by stakeholders rather than by CAISO alone. Real-time dispatch is supported as well except on the item of the ISO resolving intra-zonal congestion problems outside the optimization program. Participants would like to see a better-defined and transparent process.

\subsubsection{Transmission Expansion}

The California ISO does not own transmission facilities and does not expand the system itself. Transmission owners file annual transmission expansion plans to meet reliability and commercial needs, which the ISO approves or recommends modifications too. The ISO also works with regional transmission groups and WSCC to ensure that expansion projects do not adversely impact the regional grid. (California ISO, 2001a) Unfortunately, transmission enhancement in California, as in the rest of the U.S., is problematic and actually getting new facilities built is difficult. The ISO reports approving 129 transmission enhancement projects worth \$1.07 billion from 1998 through 2000. 
They do not report on how many have been built or how many have had construction started. (California ISO 2001b)

The cost of transmission enhancements is to be born by the beneficiaries in proportion to the benefit they receive, if they can be explicitly identified. If specific beneficiaries can not be determined, then the transmission owner pays for the enhancement and the cost is passed to all customers through the transmission access charge. (California ISO 2000)

\subsection{PJM}

PJM (Pennsylvania, New Jersey, Maryland) was initially established as a power pool in 1927. The PJM service area includes all or part of Pennsylvania, New Jersey, Maryland, Delaware, Virginia, and the District of Columbia. PJM operates the largest centrally dispatched control area in North America. Geographically, the system corresponds to the NERC Mid-Atlantic Area Council (MAAC) (see Figure 4.3.1) encompassing about 50,000 square miles and serving more than 23 million people. The system dispatches approximately $58,000 \mathrm{MW}$ of installed generating capacity--nearly $8 \%$ of the nation's total. It operates over 8,000 miles of bulk power transmission facilities. (NERC 2001b). PJM serves a large load relative to its transmission system. It has approximately 7.3 MW of demand per mile of high voltage transmission circuit ( $230 \mathrm{kV}$ and above). This compares to 5.5 for the U.S. portion of the Eastern Interconnection and 2.1 for the Western U.S. Interconnection. The PJM load is primarily within its eastern portion while much of its generation is in the western portion. In 1996 PJM's energy generation was predominantly coal $(42 \%)$ and nuclear (34\%). It was connected to the New York Power Pool, The Cleveland Electric Illuminating Co., Allegheny Power Systems, and Virginia Power (PJM 1996). In 1999 PJM imported 22,600 GWH while exporting 18,400 GWH. In 1999 PJM assumed responsibility to add new generation resources to the control area. As of 2000 , there were about $39,000 \mathrm{MW}$ of proposed capacity compared to 58,000 MW of installed capacity. (PJM 1998 and PJM 2000)

PJM Interconnection became the first operational ISO in the U.S. on January 1, 1998, managing the PJM Open Access Transmission Tariff and facilitating the Mid-Atlantic Spot Market. There is no separation of the power exchange market (PX) and the ISO. (PJM 2001a)

The PJM staff centrally forecasts, schedules, and coordinates the operation of generating units, bilateral transactions, and the spot energy market to meet load requirements. To maintain a reliable and secure electric system, PJM monitors, evaluates and coordinates the operation of over 8,000 miles of high-voltage transmission lines. The PJM OASIS is used to reserve transmission service. Operations are closely coordinated with neighboring control areas, and information is exchanged to enable real-time security assessments of the transmission grid. PJM provides accounting services for energy, ancillary services, transmission services, and capacity reserve obligations. (PJM 2001a) 


\subsubsection{Locational Marginal Pricing}

PJM manages congestion through a market design based on Locational Marginal Pricing. The Locational Marginal Price (LMP) is defined as: "The marginal cost of supplying the next increment of electric demand at a specific location (node) on the electric power network, taking into account both generation marginal cost and the physical aspects of the transmission system." (Ott 1998) Figure 4.3.1 provides a representation of the PJM Locational Marginal Pricing Model.

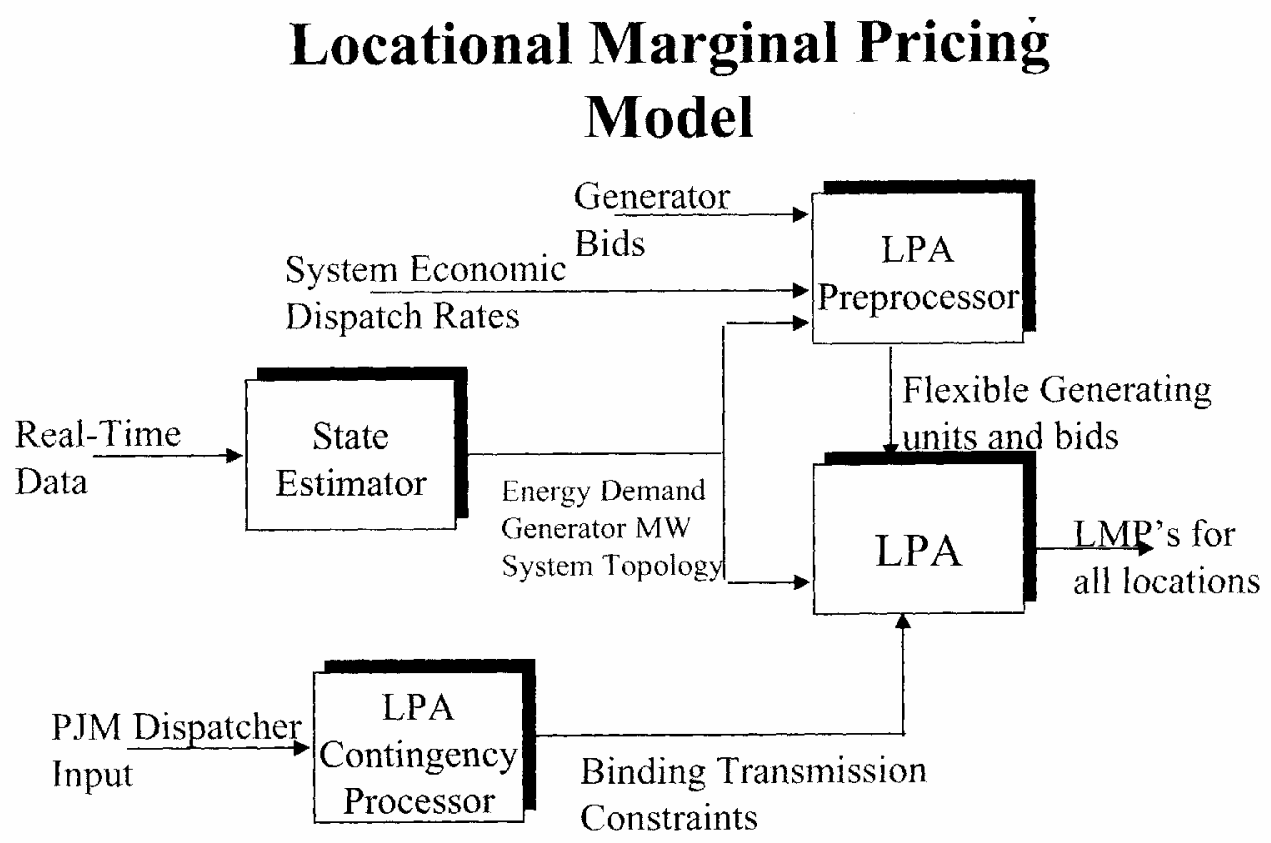

Fig. 4.3.1 PJM Locational Marginal Pricing Model

Source: Ott 1998

Model Components for Locational Marginal Pricing

State Estimator

- Model of the conditions that currently exist on the PJM power system based upon metered input and an underlying mathematical model.

Locational Price Algorithm (LPA)

- Calculates locational marginal prices based on actual system conditions at fiveminute intervals

LPA Contingency Processor

- A mechanism for PJM dispatchers to enter binding transmission constraints and controlling actions into the LMP calculation process. 
LPA Preprocessor

- Determines which generating units are eligible to participate in the LMP calculations

\subsubsection{Determining Locational Marginal Prices}

The LMPs used by PJM are location specific. They include the marginal cost of generation and the cost to deliver energy to the specific location due to congestion. The LMPs are generated at five-minute intervals and immediately posted on OASIS. The LMPs are calculated for 1,750 PJM busses plus 5 interface busses into the PJM control area. When there are no congestion constraints in the PJM system, then the LMPs are the same at all busses and equal to the marginal cost to serve load in the control area. (PJM 1998)

The LMPs are calculated by minimizing the difference between the bids for generation and load subject to transmission constraints. The LMP model generates sensitivity factors from the transmission constraints that determine the dispatch of generating units. These sensitivity factors are calculated to avoid congestion at the lowest systemwide cost. For locations (busses) where there are transmission constraints, the dispatched units (in order to operate within the constraint) will have higher costs than the lowest marginal cost-generating unit. The increase over the marginal costgenerating unit will depend on the dispatch necessary to meet the loads within the transmission constraints.

All power transactions pay the LMP for the relevant busses regardless of whether the transaction results from dispatch by the SO or the transaction is bilateral (self scheduled).

\subsubsection{Markets for FTRs}

Overlaying the LMPs for power in the PJM system is a market for FTRs ${ }^{5}$. The FTR is not a physical right to transmission service. Rather it gives the holder the right to be compensated for the difference between the LMP at the generation source and the LMP at the load. It entitles the holder to receive revenues (or charges) based on transmission congestion measured as the hourly energy LMP differences across a specific path in the day-ahead market. FTRs are originally obtained in auctions by Network Transmission Service Holders or by those with Firm Point-to-Point Transmission Reservations. They can be traded on a secondary market. This provides a hedge for the congestion costs.

FTRs may be obtained for various combinations of single or multiple busses for which an LMP is calculated and posted. These combinations of busses include hubs, zones, aggregates, and single busses either internal or external to PJM. Auction FTRs may be designated between any injection and withdrawal points.

PJM has defined three trading hubs for FTRs. These include a Western Hub with 111 busses, an Eastern Hub with 277 busses, and an Interface Hub with 3 busses. These

\footnotetext{
${ }^{5}$ PJM uses the term Fixed Transmission Rights.
} 
hubs provide a common point for commercial trading contracts. Hubs are used to create prices by weighting an aggregation of buss prices. This weighted hub price reduces the risk of individual busses which can be volatile when transmission constraints come into play. (PJM 1998)

\subsubsection{Emergency Procedures}

If designated transmission facilities reach overload conditions, and PJM has redispatched internal generation to the extent feasible, PJM will 1) use the NERC TLR Procedure; 2) curtail external customers or charge these external customers for congestion; and 3) curtail remaining transactions in order of priority. The PJM customers have some choice in that external transmission customers can choose to pay congestion charges during TLR in the PJM control area and internal customers may voluntarily curtail transactions if congestion charges become too large (PJM 2001b).

\subsubsection{Transmission Expansion}

PJM uses a centralized process to plan transmission expansion. The costs plus a reasonable return are recovered through contracts and tariffs for use of the facilities. The Regional Transmission Owners must unanimously agree on the allocation of costs or costs are assigned based on the size or the voltage of the facility and the zone where the facility is to be located. (PJM 2001c) 


\section{Conclusions and Recommendations}

With the advent of deregulation and policies of open access, allocation of scarce transmission resources has become a key factor for the efficient operation of electricity markets as well as reliability and control of market power. This trend has been reinforced as expansion of the transmission capacity has failed to keep pace with the demand for power and the emerging trends to transfer power over longer distances. These trends make it increasingly important that congestion management is structured to facilitate economically efficient allocation of transmission capacity. Because of the policies of open access coupled with the inability to economically control flows on individual lines within an AC power system, transmission capacity is characterized as a communal resource and otherwise subject to the externalities of overuse. Congestion management can also provide insight into where transmission enhancements are needed.

The restructuring of generation and transmission resources not only requires new approaches to congestion management but also provides an opportunity for them. As might be expected, congestion management is in a period of tremendous flux. Serious debates over the best approach to allocate transmission resources to support competitive markets are taking place. New approaches are being implemented, and these will provide feedback about how congestion management can best support efficiency and reliability. As these approaches are made operational, they will provide real-world experience that will provide the basis for evaluating the most effective techniques for congestion management.

A key question for any ISO or policy-maker is whether congestion management is effectively and efficiently achieving its objectives. For this purpose it would be useful to have standard measurements. In fact, several metrics are routinely used to measure the effects of congestion. The following is a list of several metrics that have been used to measure the importance of congestion:

- TLR-based measures including the number and degree of actions taken over a given period

- Frequency of curtailments

- Duration of curtailments

- Megawatts of curtailments

- Energy of curtailments

- Energy not served

- Bulk Power Interruption Index (Capacity/Peak Load)

- Bulk Power Energy Curtailment Index (Energy/Peak Load)

- System Minutes (summation of MW not exchanged $x$ minutes of duration)

- Congestion costs (difference between system costs with and without congestion)

- Congestion rents (energy flow between congested nodes $x$ marginal cost difference between nodes) 
The optimal amount of congestion is achieved where any change results in higher system costs. An index to measure congestion management should help determine how to move closer to the optimal amount of congestion. For instance, if an expansion in transmission facilities reduces congestion but increases overall costs including the cost of making the investment, then this moves away from the goal of achieving optimal congestion.

It is important to note that the list above contains measures of congestion, not congestion management. A conceptual definition of a metric for congestion management would be: The difference between congestion effects under scheme 1 compared to scheme 2 for a given level of reliability. This definition points out some of the challenges in developing an index of congestion management.

First, a congestion management metric involves a difference for which all variables other than the congestion management scheme should remain constant. A high rate of congestion may reflect inadequate transmission investment as opposed to ineffective congestion management. In other words, there must be both a metric of congestion and a standard against which to measure that metric.

Second, if a transmission system implements a new scheme, a valid congestion management metric must consider any change in reliability. Has the new scheme reduced congestion metrics at the cost of reliability? If it did, was this a desirable tradeoff? Can a reliability metric be incorporated into the congestion management metric? At what rate should reliability be traded against commercial objectives or are reliability standards set independently?

Third, a valid congestion management metric would be able to account for the divergence from some optimal level of efficient operations. For instance, if curtailments are reduced through incentives that discourage transactions, then congestion may be reduced at the cost of system efficiency. This suggests the appeal of allocating congestion through a market system of prices that reflect the value of the system's congested facilities. 


\section{Acknowledgement}

The authors gratefully acknowledge the funding for this project provided by the California Energy Commission and the Assistant Secretary for Energy Efficiency and Renewable Energy, Office of Power Technologies, Transmission Reliability Program of the U. S. Department of Energy.

We would also like to thank Susan Johnsen for her assistance in editing and preparing this report.

\section{References}

Z. Alaywan 2001, The California Firm Transmission Rights, Energy and Power Risk Management, U.K., March

Z. Alaywan 1999, Facilitating the Congestion Management Market in California, IEEE PES Conference Proceeding Paper, Edmonton, Canada, Summer

California ISO 1998, Strategic Plan for the California Independent System Operator, Folsom Ca, October

California ISO 2000, California Independent System Operator Corporation FERC Electric Tariff, First Replacement Volume No. 1, Folsom Ca, October

California ISO 2001a, www.caiso.com, December

California ISO 2001b, California Independent System Operator 2000 Annual Report, Folsom $\mathrm{Ca}$

ERCOT 2001a, www.ercot.com, December

ERCOT 2001b, Operating Procedure Manual, Transmission Security Desk, Version 1.0 Rev 1, Electric Reliability Council of Texas, November 16

ERCOT 2001c, Operating Procedure Manual, Operating Period Desk, Version 1.0 Rev 1, Electric Reliability Council of Texas, August 27

ERCOT 2001d, Congestion Protocol - Section 7, Electric Reliability Council of Texas, September 7

ERCOT 2001f, http://mospublic.ercot.com/ercot/jsp/commercially significant constraints.jsp, downloaded December 7 
E. Lo, K. Xie, J. Sentil, Z. Alaywan, and M. Rothleder 2001, Flexible Adjustable Inter-SC Trades Modeling in Congestion Management, IEEE PES Transaction, Vancouver, Canada, Summer

J. McClain 2001, Overview of Firm Transmission Rights, California ISO, www.caiso.com, December

NERC 2001a, NERC Operating Manual, Princeton, NJ, July

NERC 2001b. http://www.nerc.com/regional/maac.html, December

NERC 2001c. Open Access Same-Time Information System, Phase II, Ferc Docket. No. RM 00-10-000, February 8, 2001

PJM 1996 (PJM Interconnection Facts-1996

www.pim.com/market system data/statistics/1996.html)

PJM 1998. PJM LMP Implementation Training www.PJM.com

PJM 2000 PJM Interconnection State of the Market Report 1999 www.pjm.com/market monitoring/reports.html

PJM 2001c. Amended and Restated Operating Agreement of PJM Internconnection, L.L.C., March 15, 2001 www.pim.com/documents/FERC/2001docs/

PJM 2001a. Who We Are--What We Do, www.pjm.com/about/general.html , December

PJM 2001b Emergency Operations, Revision 11. Effective Date June1, 2001. http://pubs.pjm.com:80/dynaweb/PJMpubp/m13/@Generic_BookView

A. L. Ott 2000. Can Flowgates Really Work? An Analysis of Transmission Congestion in the PJM Market from April1, 1998-April 30, 2000., PJM Internconnection, www.pjm.com, Sept. 15

A. L. Ott 1998. PJM Locational Marginal Pricing model, Andrew Ott, PJM Interconnection, L.L.C. July 30, 1998--a pdf file of slides) See: www.pjm.com/training/downloads/ferc_pres.pdf\#xml=http://www.pjm.com/search97cgi/s 97_cgi?action=View\&VdkVgwKey=http\%3A\%2F\%2Fwww\%2Epjm\%2Ecom\%2Ftrainin

Ruff 2001. Flowgates, Contingency-Constrained Dispatch, and Transmission Rights, The Electricity Journal, January/February

WSCC 2001, www.wscc.com, December 


\section{INTERNAL DISTRIBUTION}

1. M. A. Brown, $4500 \mathrm{~N}, \mathrm{MS}-6186$

2. J. E. Christian, 3147 , MS-6070

3. P. D. Fairchild, 3147, MS-6070

4-8. B. J. Kirby, 3147, MS-6070

9-13. J. W. Van Dyke, 4500N, MS-6205

14. ORNL Central Research Library, $4500 N$, MS-6191

15-16. Laboratory Records, 4500N, MS-6285

\section{EXTERNAL DISTRIBUTION}

17. Fernando L. Alvarado, Professor, Department of Electrical and Computer Engineering, University of Wisconsin-Madison, 2544 Engineering Hall, 1415 Engineering Drive, Madison, WI 53706

18. Vikram Budhraja,President, Electric Power Group, LLC, 201 South Lake Avenue, Suite 400, Pasadena, CA 91101

19. Jim Dyer, Electric Power Group, LLC, 201 South Lake Avenue, Suite 400, Pasadena, CA 91101

20-24. Joseph Eto, CERTS Program Manager, Lawrence Berkeley National Laboratory, Bldg. 90 Room 4126K, MS: 90-4000, University of California, Berkeley, CA 94720

25. Charles Goldman, Environmental Energy Technology, Lawrence Berkeley National Laboratory, 1 Cyclotron Road, MS: 90-4106, Berkeley, CA 94720

26. George Gross, Professor, Department of Electrical and Computer Engineering, University of Illinois at Urbana-Champaign, 339 William L. Everitt Laboratory, 1406 West Green Street, Urbana, IL 61801

27. Carl Imhoff, Product Line Manager for Energy Operations and Maintenance, Pacific Northwest National Laboratory, 902 Battelle Boulevard, P. O. Box 999, Richland, WA 99352

28. Mark Levine, Director, Environmental Energy Technologies Division, Lawrence Berkeley National Laboratory, 1 Cyclotron Road, Bldg 90, Room 3126, Berkeley, CA 94720

29. Chris Marnay, Energy Analysis, Lawrence Berkeley National Laboratory, 1 Cyclotron Road, MS 90-4000, Berkeley, CA 94720

30-34. Carlos Martinez, Electric Power Group, LLC, 201 South Lake Avenue, Suite 400, Pasadena, CA 91101

35. Timothy Mount, Professor, Applied Economics and Management, 214 Warren Hall, Cornell University, Ithaca, NY 14853-7801

36. Shmuel S. Oren, Department of Industrial Engineering and Operations Research, 4135 Etcheverry Hall, University of California at Berkeley, Berkeley, CA 94720 
37. Alonso Rodriguez, Electric Power Group, LLC, 201 South Lake Avenue, Suite 400, Pasadena, CA 91101

38. William Schulze, Professor, Applied Economics and Management, 301 Warren Hall, Cornell University, Ithaca, NY 14853-7801

39. Richard E. Schuler, Professor, Civil and Environmental Engineering and Economics, 466 Uris Hall, Cornell University, Ithaca, NY 14853-7801

40. Sarosh N. Talukdar, Carnegie Mellon, ECE Department, Pittsburgh, PA 15213

41. Marjorie Tatro, Director, Energy and Transportation Security Department, Sandia National Laboratory, 1515 Eubank SE, Albuquerque, NM 87185-0704

42. Robert J. Thomas, Director, Power Systems Engineering Research Center, Cornell University, 428 Phillips Hall, Ithaca, NY 14853 